\title{
Quantification of sediment reworking rates in bioturbation research: a review
}

\author{
Olivier Maire ${ }^{1, *}$, Pascal Lecroart $^{2}$, Filip Meysman ${ }^{3}$, Rutger Rosenberg $^{4}$, \\ Jean-Claude Duchêne ${ }^{5,6}$, Antoine Grémare ${ }^{7}$ \\ ${ }^{1}$ Oceanlab, University of Aberdeen, Newburgh, Aberdeenshire AB41 6AA, UK \\ ${ }^{2}$ Université Bordeaux 1, CNRS, UMR 5805 EPOC, Avenue des Facultés, 33405 Talence, France \\ ${ }^{3}$ Laboratory for Analytical and Environmental Chemistry, Vrije Universiteit Brussel (VUB), Pleinlaan 2, 1050 Brussel, Belgium \\ ${ }^{4}$ Department of Marine Ecology, Göteborg University Kristineberg Marine Research Station, 45034 Fiskebäckskil, Sweden \\ ${ }^{5}$ Université Pierre \& Marie Curie-Paris 6, and ${ }^{6}$ CNRS, UMR 7621, LOBB, Observatoire Oceanologique, \\ 66651 Banyuls-sur-Mer, France \\ ${ }^{7}$ Université Bordeaux 1, CNRS, UMR 5805 EPOC, Station Marine d'Arcachon, 2 rue du Professeur Jolyet, 33120 Arcachon, France
}

\begin{abstract}
This review lists and discusses the different methods currently available to assess sediment reworking by benthic infauna. Direct methods are used to estimate the amount of sediment transported by infauna at the sediment-water interface during a given period of time. Particle-tracer methods are used to quantify the vertical distribution of particle tracers within the sediment column. Tracers are classified based on their mode of introduction at the sediment-water interface (i.e. whether they occur naturally or are deliberately introduced at the onset of the experiment). The main characteristics of each method, including modelling aspects, are presented, and their respective advantages and drawbacks are outlined with a particular emphasis on their accuracy, spatial (i.e. both horizontal and vertical) and temporal resolutions. Direct and particle-tracer methods assess different components of sediment reworking. Selection of the most appropriate approach depends on the specific question(s) to be answered, as well as other factors, including the behaviour of the organisms studied, the spatial and temporal scales considered, and whether the experiments are carried out in situ or under controlled laboratory conditions.
\end{abstract}

KEY WORDS: Sediment reworking $\cdot$ Bioturbation $\cdot$ Tracer $\cdot$ Radionuclides $\cdot$ Luminophores $\cdot$ Modelling $\cdot$ Particle dispersal

Resale or republication not permitted without written consent of the publisher

\section{INTRODUCTION}

The process of bioturbation, which involves both the dispersal of sediment particles (i.e. sediment reworking) and the transport of interstitial porewater (i.e. bioirrigation) by benthic organisms, is of global importance, as it occurs in most oxic sediments. Through various activities (mainly feeding, burrowing, locomotion and ventilation), benthic fauna modifies the physical, chemical and biological properties of the sediment (Rhoads 1974, Aller 1982, Lohrer et al. 2004). Bioturbation affects, in particular, fluxes of nutrients, oxygen, contaminants and pollutants, and more generally strongly influences the process of organic matter mineralization near the sediment-water interface (Lee \& Swartz 1980, Aller 1982, Gilbert et al. 1995, Kristensen
2000, Furukawa et al. 2001). Accordingly, characterizing and quantifying bioturbation processes is of primary importance to unravel the tight and complex mechanisms that control benthic ecosystem functioning at different spatial and temporal scales. To date, a large variety of methods have been developed to assess bioturbation. In this review, we focus solely on those that are used to quantify particle dispersal. Common approaches are either based on the direct quantification of the amount of sediment reworked (direct methods) or on the fitting of mathematical models to vertical profiles of tracer concentrations (particle-tracer methods).

The choice of a method depends on the characteristics of the site and organisms that are studied, and on the scientific purpose. No consensus has been reached on a 'standard' method for the assessment of sediment re- 
working. For example, it is still a matter of discussion whether exotic tracer particles such as glass beads or luminophores are suitable to assess sediment reworking (Wheatcroft et al. 1994). Moreover, the most commonly used particle-tracer methods only provide a 1-dimensional (1D) assessment of sediment reworking (Maire et al. 2006). Another debate concerns the type of mathematical model that should be used to quantify sediment reworking from vertical tracer distributions (Meysman et al. 2003). Sediment reworking has most often been considered as analogous to diffusion, which assumes that displacements of individual particles are very frequent and occur randomly over very short distances (Boudreau 1986a). These assumptions are most often not met (Boudreau 1986a, Meysman et al. 2003), and this has led to the development of a series of models adapted to each main reworking mode (François et al. 1997, 2001) and to more generalized non-local transport models (Boudreau \& Imboden 1987, Meysman et al. 2003, Maire et al. 2007a). Despite such developments, the biodiffusive model is still widely used, because of its simplicity and its ability to fit tracer profiles well. This striking contradiction between modelling theory and field practice has been referred to as the 'biodiffusion paradox' (Meysman et al. 2003).

The aims of this review are to (1) list the methods currently available to assess sediment reworking both in situ and during laboratory experiments; (2) discuss their main characteristics, including modelling aspects, relative advantages and drawbacks; and (3) present some new and promising approaches that allow for a more complete and/or accurate assessment of sediment reworking in relation to faunal activity.

\section{DIRECT METHODS}

Direct methods estimate the amount of sediment handled during a given period of time by (1) collecting the sediment brought up by organisms to the sediment-water interface (Rhoads 1963, 1967, Cadée 1976, Dobbs 1983, Hughes et al. 1996, Rowden et al. 1998, Berkenbusch \& Rowden 1999) or (2) estimating the volume of sediment displaced using non-destructive techniques such as image analysis (Hollertz \& Duchêne 2001, Lohrer et al. 2005) or laser telemetry (Maire et al. 2007b). Five main approaches have been developed to assess sediment displacement: directcollection of castings, entrapment, levelling, microtopography, and image analysis (Table 1).

\section{Direct collection of castings}

The collection of sediment brought by organisms to the sediment-water interface was first introduced by

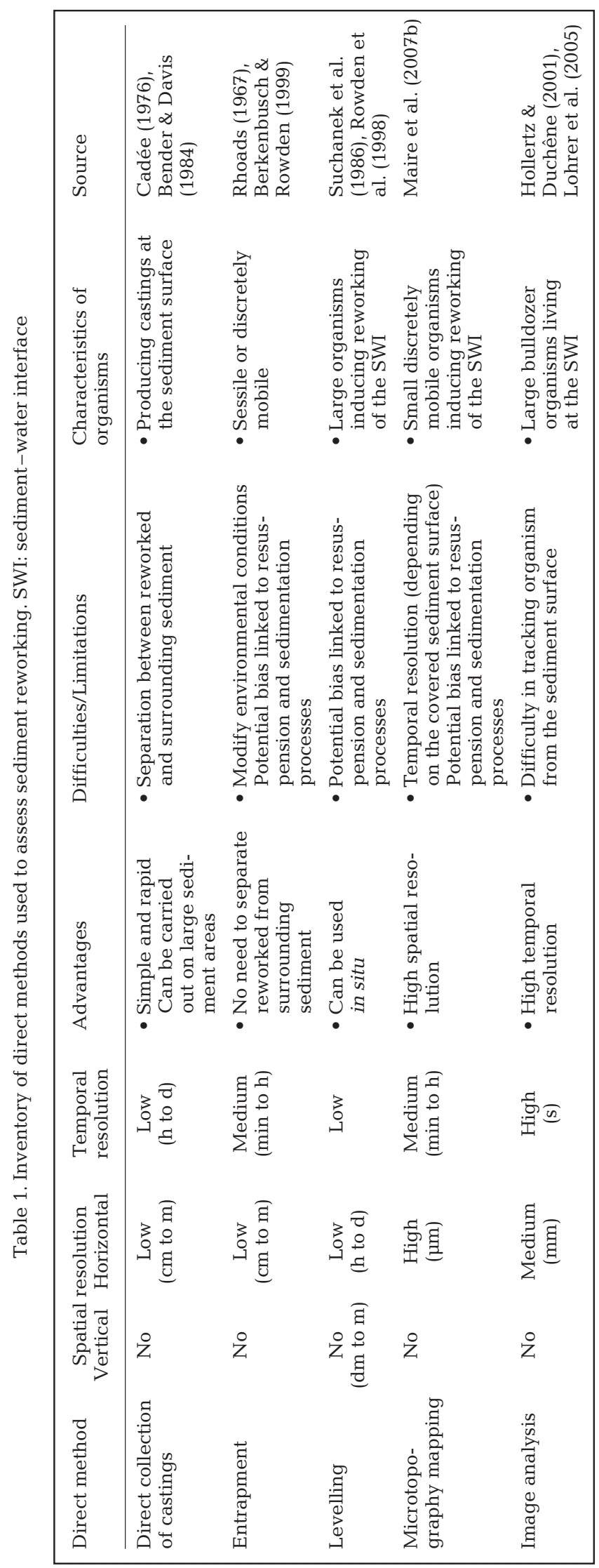


Davison (1891). Later, it was used, for example, by Cadée (1976) to estimate in situ sediment reworking by the lugworm Arenicola marina. Castings were collecting at low tide, and their amounts were standardized relative to immersion duration and sediment area. Direct collection assumes that all the sediment expelled at the sediment-water interface can be collected separately from the surrounding sediment. This often proves difficult, since a great proportion of reworked sediment may be unconsolidated and spread laterally (Cadée 1976, Bender \& Davis 1984), which likely results in an underestimation of sediment reworking.

\section{Entrapment}

Entrapment consists of placing a trap (e.g. a piece of filter paper, aluminium foil, or a cylindrical tube) around the site of sediment expulsion (i.e. typically the opening of a burrow, a tube, or a siphon channel) (Fig. 1). After a known period of time, the trap is retrieved and the amount of collected (i.e. reworked) sediment is measured. This approach has been used for a large variety of benthic infauna, including polychaetes (Rhoads 1967, Nichols 1974, Kudenov 1982), bivalves (Rhoads 1963) and crustaceans (Berkenbusch \& Rowden 1999), both in situ and during laboratory experiments. Sediment entrapment enables a more complete account of sediment reworking, including some of the unconsolidated faeces, pseudofaeces and burrow ejecta even if a portion of them can be lost through resuspension. The entrapment method is restricted to sessile or discretely motile organisms, and the presence of the trap may modify local environmental conditions such as hydrodynamics.

The 2 direct methods described above are exclusively based on the collection of sediment deposited at the sediment-water interface. These techniques are simple and straightforward, and, historically, they were the first to be used to estimate sediment reworking rates (Davison 1891, Rhoads 1963, 1967). Besides the technical drawbacks mentioned above, they do not allow for high-frequency measurements and do not provide any insights on where the sediment originates. Other direct methods involving sediment micro-topography mapping and image analysis have been recently developed to overcome these drawbacks (Table 1).

\section{Levelling and microtopography mapping}

Levelling consists of recording temporal changes in the height of the sediment-water interface during either laboratory (Rhoads 1967) or in situ experiments (Suchanek et al. 1986). The original sediment-water

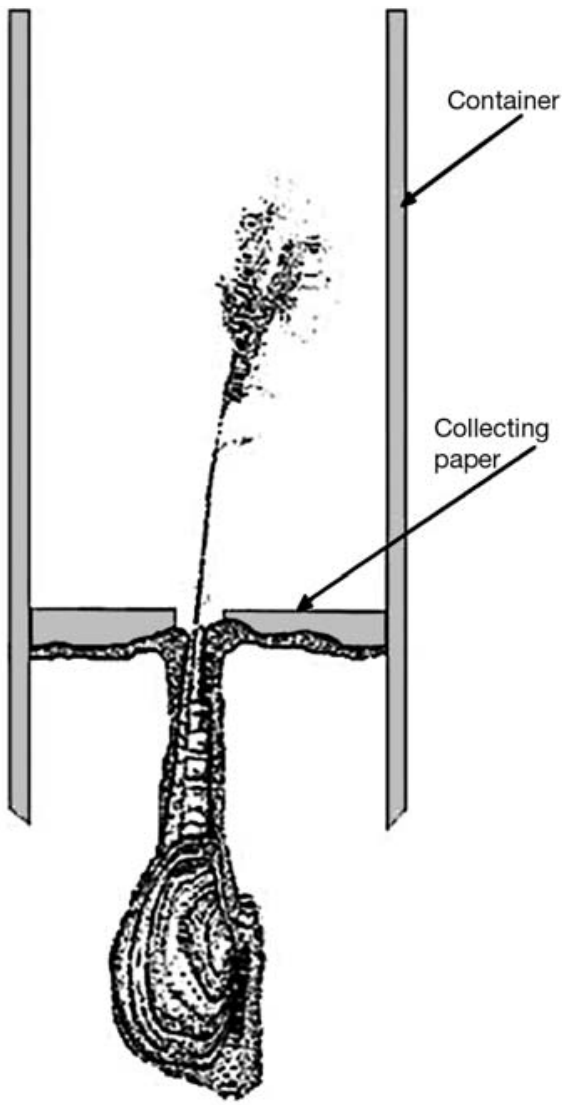

Fig. 1. Principle of the entrapment method. The volume of reworked sediment ejected at the sediment-water interface by the organism (for example Yoldia limatula; Bender \& Davis 1984 ) is collected in a trap placed around the site of sediment rejection (modified from Rhoads 1963)

interface is used as a reference, and the sediment accumulated above this level is assumed to result from sediment reworking. This sediment can either be periodically collected and weighed (Rhoads 1967, Rowden et al. 1998), or its volume can be estimated from sequential measurements of the level of the sediment-water interface (Suchanek et al. 1986).

This approach has been recently improved by microtopography mapping. The amount of reworked sediment is then estimated through the assessment of temporal changes in microtopography of the sediment surface (Roy et al. 2002, 2005, Maire et al. 2007b) (Fig. 2). Two main techniques of data acquisition are used. (1) Projecting a laser line onto the sediment surface and comparing its position between successive images; this allows the mapping of sediment microtopography with a ca. $50 \mu \mathrm{m}$ vertical and a high temporal resolution (Roy et al. 2002, 2005). (2) Using a laser telemeter mounted on 2 crossed step motor tables allowing for 2D displacements above the studied sediment surface (Maire et al. 2007b); this provides both high horizontal $(200 \mu \mathrm{m})$ and vertical $(15 \mu \mathrm{m})$ resolutions, and, thus, an accurate estimation 


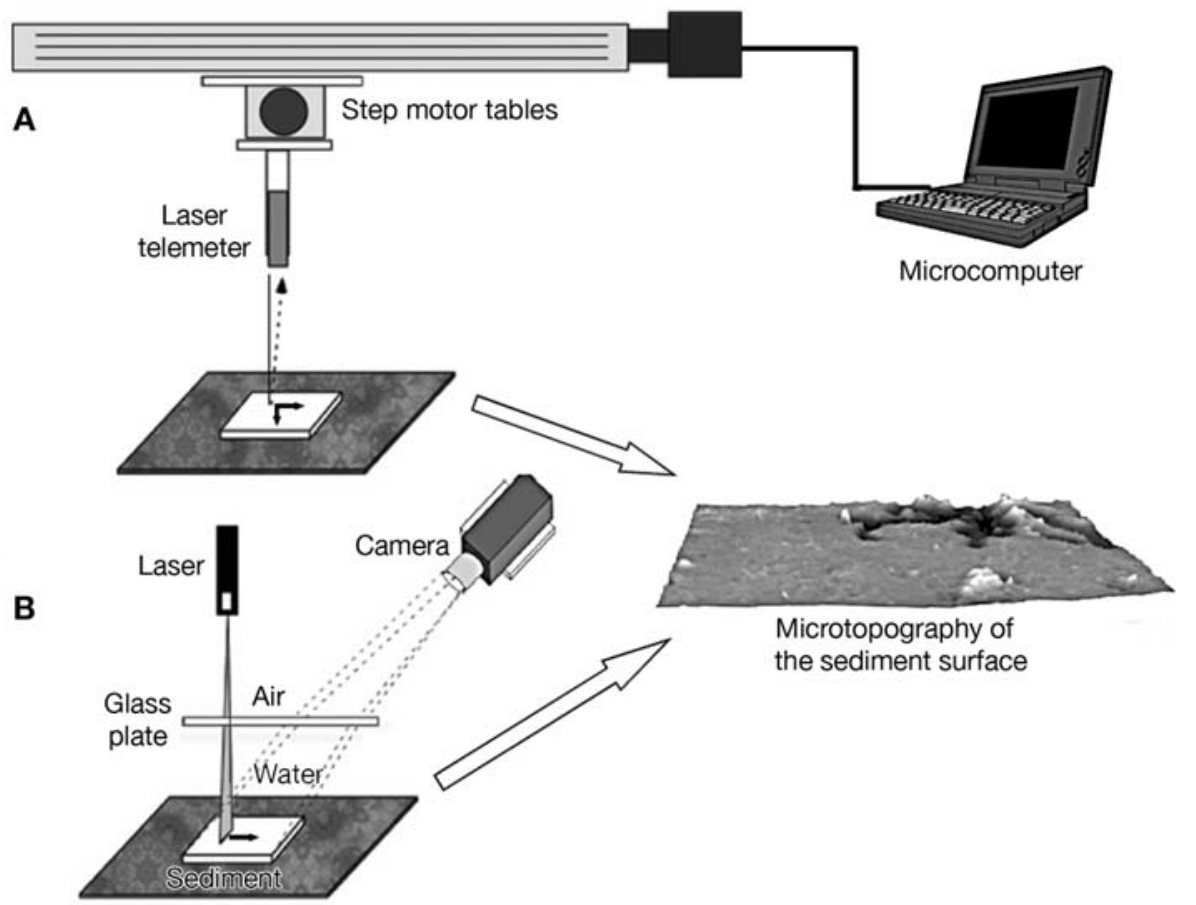

Fig. 2. Principle of the microtopography mapping method. The amount of reworked sediment is estimated through the assessment of temporal changes in the microtopography of the sediment surface. Successive microtopography mappings can be assessed: (A) using a laser telemeter mounted on 2 crossed step motor tables allowing for 2-dimensional displacements above the sediment surface (modified from Maire et al. 2007b) or (B) through the projection of a laser line onto the sediment surface. A glass plate placed at the air-water interface assures welldefined and constant refraction. An image of the projected laser line is recorded by a digital camera. The position of the laser line in the image is then determined, allowing for estimations of sediment surface elevations (modified from Roy et al. 2002)

of sediment reworking at the sediment-water interface between 2 successive scans ( $S R$ ):

$$
S R=\frac{\sum_{i, j}|\Delta L W S I|}{\Delta t}
$$

where $i$ and $j$ correspond to the $x$ and $y$ coordinates in the sediment area, $\Delta L W S I$ represents the differences of levels of the sediment-water interface of the scanned area between 2 consecutive scans, and $\Delta t$ is the time interval between 2 consecutive scans.

The first technique is limited by the length of the laser line (typically $5 \mathrm{~cm}$ ) and cannot provide microtopography measurements behind sediment mounds or within sharp pits. The main disadvantage of laser telemetry is the time required to run each scan (e.g. 67 min for a $64 \mathrm{~cm}^{2}$ sediment surface; Maire et al. 2007b); this limits its temporal resolution. Moreover, when used during in situ experiments, levelling and microtopography mapping may result in erroneous estimations of sediment reworking, since reworked sediment may be transported out of the monitored area. Conversely, part of the sediment accumulated at the sediment-water interface may result from the sedimentation of resuspended material.

\section{Surface image analysis}

Surface image analysis involves the recording of the movements of benthic fauna at the sediment surface using a video sensor (Hollertz \& Duchêne 2001, Lohrer et al. 2005) (Fig. 3). In each image, the position of the organism is automatically detected, and its coordinates within the image are recorded. At the end of the experiment, all coordinates, within successive images, are used to assess displacements. Sediment reworking rates $(S R)$ are then computed as:

$$
S R=\frac{(D T \times C S)}{\Delta t}
$$

where $D T$ is the distance travelled during a $\Delta t$ time interval, and $C S$ is the cross section, i.e. the reworked area along the plane of locomotion.

This approach has been used for sea urchins both in situ (Lohrer et al. 2005) and during laboratory experiments (Hollertz \& Duchêne 2001). Its main advantage is that it allows for the assessment of short-term temporal changes in sediment reworking (Hollertz \& Duchêne 2001). In practice, its use is restricted to large organisms living immediately beneath the surface of the sediment, so that their movements can be tracked by monitoring the sediment-water interface. Moreover, it does not account for sediment reworking resulting from processes other than locomotion (e.g. feeding), which makes it particularly suitable for bulldozing organisms such as spatangoid sea urchins, where the ratio of sediment reworking caused by locomotion over that caused by feeding is between 60 and 150 (Hollertz \& Duchêne 2001).

\section{PARTICLE-TRACER METHODS}

Particle-tracer methods were introduced to study the vertical component of sediment reworking. They are 


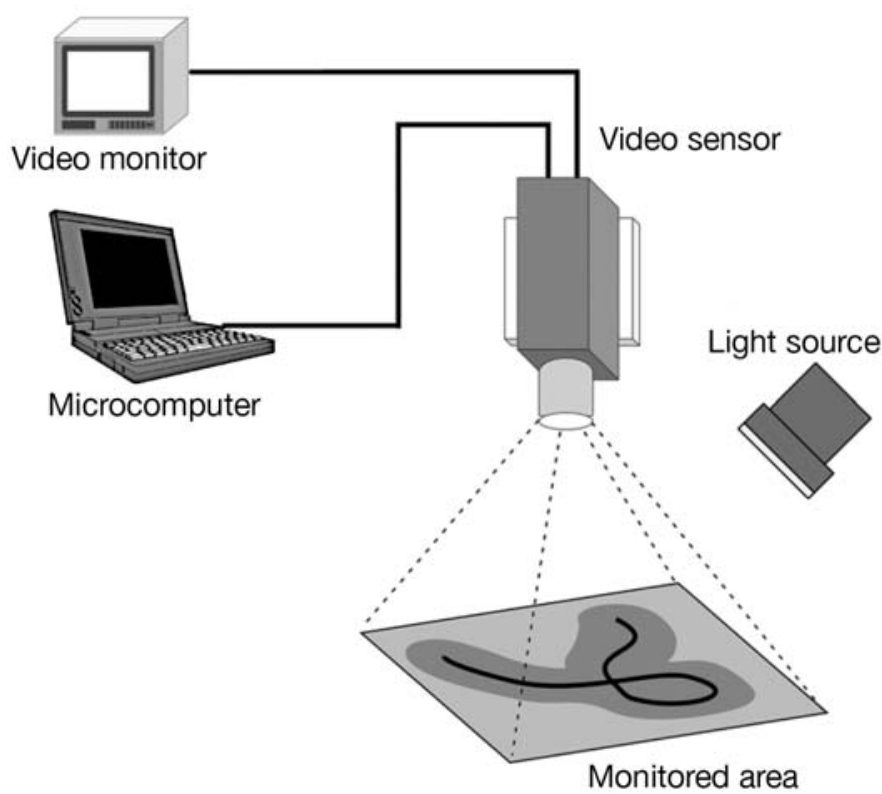

Fig. 3. Principle of the image analysis method. The position of the organism is automatically detected at the surface of the monitored sediment area, and its coordinates are recorded. At the end of the experiment, all coordinates, within successive images, are compiled to assess its displacements. The reworked volume of sediment is then estimated based on the linear track (i.e. the distance travelled during the time interval considered) and the cross section of the organism

based on the measurement of the vertical distribution of particle tracers within the sediment column. The underlying principle is that tracers initially deposited at the sediment-water interface, or placed at some horizon within the sediment column (see Gilbert et al. 2007), are displaced due to the action of benthic fauna. Sediment reworking coefficients are then computed using mathematical models that are fitted to the vertical tracer profile (Boudreau 1986a,b, Wheatcroft et al. 1990, François et al. 1997, 2001, Meysman et al. 2007) (Fig. 4).
Particle tracers are supposed to behave in the same way as sediment particles. The high diversity of particle-tracer methods focuses on: (1) type of tracers that differ in terms of stability, reactivity, association with sediment particles, and mode of introduction to the sediment-water interface, (2) recovery and quantification of the tracers, and (3) type of model used to infer sediment reworking coefficients.

\section{Diversity and characteristics of particle tracers}

Tracers can be classified depending on their mode of introduction at the sediment-water interface, irrespective of whether they are natural or deliberate, and whether they are non-conservative (initial mass of the tracer decreases over time as the tracer is degraded through chemical reactions within the sediment) or conservative (initial mass of the tracer remains constant over time) (Table 2).

\section{Naturally occurring tracers}

Radionuclides. During the last 3 decades, radionuclides have been the most widely used particle tracers to assess sediment reworking rates in aquatic environments (Krezoski et al. 1984, Sharma et al. 1987, Green et al. 2002). Some radionuclides occur naturally in the water column, such as ${ }^{210} \mathrm{~Pb},{ }^{234} \mathrm{Th},{ }^{228} \mathrm{Th},{ }^{32} \mathrm{Si},{ }^{14} \mathrm{C}$ and ${ }^{7} \mathrm{Be}$ (Aller 1982). Most of them originate from atmospheric fallout. For example, ${ }^{210} \mathrm{~Pb}$ is produced from ${ }^{222} \mathrm{Rn}$ decay in the atmosphere and by ${ }^{226} \mathrm{Ra}$ decay in the water column. ${ }^{234} \mathrm{Th}$ is produced by the decay of dissolved ${ }^{238} \mathrm{U}$ in the water column. ${ }^{7} \mathrm{Be}$ is produced by the interaction of cosmic rays with atmospheric constituents and delivered to the sea surface through wet and dry deposition. All are quickly scavenged from the water

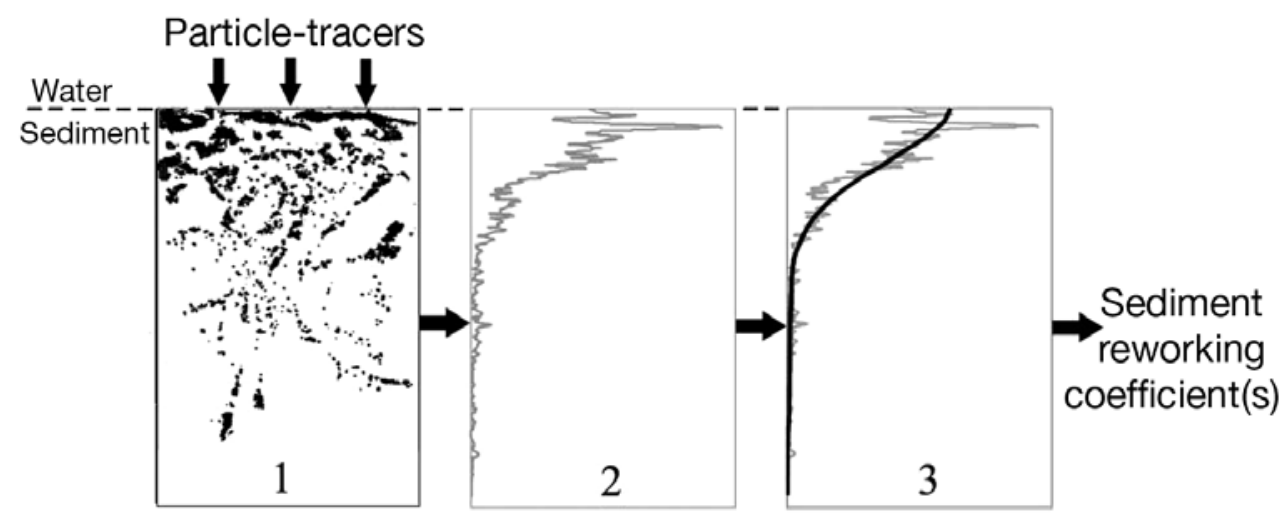

Fig. 4. Principle of particle-tracer methods. (1) Tracer particles deposited at the sediment-water interface are mixed within the sediment column due to infauna activity. (2) The vertical tracer profile is assessed using a tracer recovery method. (3) Sediment reworking coefficients are computed by fitting a mathematical model (black line) to the vertical profile (grey line) 
Table 2. Inventory of particle tracers used to assess sediment reworking

\begin{tabular}{|c|c|c|c|c|}
\hline Tracer & Temporal resolution & Advantages & Difficulties/Limitations & Source \\
\hline Radionuclides & $\begin{array}{l}\text { Medium-Low } \\
\text { (mo to century) }\end{array}$ & $\begin{array}{l}\text { - Naturally occurring in the } \\
\text { field }\end{array}$ & $\begin{array}{l}\text { - Preferential association } \\
\text { with fine particles }\end{array}$ & $\begin{array}{l}\text { Sharma et al. (1987), } \\
\text { Green et al. (2002) }\end{array}$ \\
\hline Microtektites & $\begin{array}{l}\text { Low } \\
\text { (centuries) }\end{array}$ & $\begin{array}{l}\text { - Naturally occurring in the } \\
\text { field }\end{array}$ & $\begin{array}{l}\text { - Exotic particles } \\
\text { Provide information on } \\
\text { past sediment reworking }\end{array}$ & $\begin{array}{l}\text { Glass (1969), Glass et al. } \\
(1973)\end{array}$ \\
\hline $\begin{array}{l}\text { Isotopically labelled } \\
\text { sediment particles }\end{array}$ & $\begin{array}{l}\text { High } \\
\text { (h to d) }\end{array}$ & $\begin{array}{l}\text { - Pulse input allowing for sedi- } \\
\text { ment reworking assessment } \\
\text { over short temporal scales }\end{array}$ & $\begin{array}{l}\text { - Preparation of sediment } \\
\text { particles before the experi- } \\
\text { ments }\end{array}$ & $\begin{array}{l}\text { White et al. (1987), } \\
\text { Sandnes et al. (2000a) }\end{array}$ \\
\hline $\begin{array}{l}\text { Isotopically labelled } \\
\text { organic matter }\end{array}$ & $\begin{array}{l}\text { High } \\
\text { (h to d) }\end{array}$ & $\begin{array}{l}\text { - Pulse input allowing for sedi- } \\
\text { ment reworking assessment } \\
\text { over short temporal scales }\end{array}$ & $\begin{array}{l}\text { - Positive selection of } \\
\text { organic-rich particles }\end{array}$ & Blair et al. (1996) \\
\hline Glass beads & $\begin{array}{l}\text { High } \\
\text { (h to d) }\end{array}$ & $\begin{array}{l}\text { - Pulse input allowing for sedi- } \\
\text { ment reworking assessment } \\
\text { over short temporal scales }\end{array}$ & - Exotic particles & Berg et al. (2001) \\
\hline Microtaggants & $\begin{array}{l}\text { High } \\
\text { (h to d) }\end{array}$ & $\begin{array}{l}\text { - Pulse input allowing for sedi- } \\
\text { ment reworking assessment } \\
\text { over short temporal scales }\end{array}$ & - Exotic particles & Wheatcroft (1991) \\
\hline Luminophores & $\begin{array}{l}\text { Very high } \\
\text { (min to h) }\end{array}$ & $\begin{array}{l}\text { - High frequency measurements } \\
\text { Can be used with image ana- } \\
\text { lysis recovery methods }\end{array}$ & - Exotic particles & $\begin{array}{l}\text { Mahaut \& Graf (1987), } \\
\text { Gérino (1990) }\end{array}$ \\
\hline
\end{tabular}

column by suspended particles, and transported to the sea floor, where they are rapidly incorporated and mixed into the sediment. Their vertical distribution within the sediment column depends on (1) external supply rates, (2) in situ production, (3) half-life, and (4) sediment reworking. When the values of the 3 first parameters are known, sediment reworking can be assessed based on vertical concentration profiles. Moreover, radionuclides with varied half-lives are suitable to mimic organic matter with different decay constants since, as pointed out by Aller (1982), the 2 types of decay have similar kinetics.

The main deliberate radionuclides used to assess sediment reworking rates in marine environments are radionuclides originating from nuclear testing such as ${ }^{137} \mathrm{Cs}$ (half-life $30.2 \mathrm{yr}$ ) and ${ }^{241} \mathrm{Am}$ (half-life $14.9 \mathrm{yr}$ ) (White et al. 1987, Thomson et al. 2000, Mulsow et al. 2002). They were first introduced into the marine environment in the 1950s and their concentrations peaked between 1963 and 1964 because of nuclear weapons testing (Callender \& Robbins 1993). Because of their long half-lives, these radionuclides have been used to assess sediment reworking rates over decadal time scales (Sharma et al. 1987, Thomson et al. 2000). As opposed to natural radionuclides, which are continuously supplied to the sea floor, deliberate radionuclides are not characterized by steady-state distributions and can be considered a pulse input (Aller 1982).
Chlorophyll a. Chl a is a non-conservative tracer, and is thought to track the mixing of fresh organic matter. The concentration of chl a within the sediment column depends on its sedimentation and degradation rates, and on sediment reworking. Therefore, its use as a particle tracer for sediment reworking first requires knowledge about sedimentation and degradation rates and assumes that chl a can be considered as a particle-associated sedimentary component. The half-life of chl $a$ is typically between 3 and $250 \mathrm{~d}$, depending on redox conditions (about $23 \mathrm{~d}$ on average under oxic conditions) (Sun et al. 1991, 1993, Stephens et al. 1997, Gérino et al. 1998). Accordingly, the estimation of its degradation rate may prove difficult when bio-irrigators, introducing oxygen into the sediment, are present. Another drawback of chl $a$ is that sediment reworking can be biased due to positive selection of chl a rich particles during feeding (Taghon 1982, Lopez \& Levington 1987, Mahon \& Dauer 2005). Moreover, the concentration of chl a is significantly affected during its transit through animals' guts (Abele-Oeschger \& Theede 1991), which complicates its use in the case of non-local transport associated with feeding (e.g. conveyor belt feeders).

The distributions of chl a concentrations in the sediment column have nevertheless been used to assess sediment reworking on a few occasions (Sun et al. 1991, Gérino et al. 1998, Josefson et al. 2002). 
Microtektites. Microtektites are small glass spheres (typical size range from $30 \mu \mathrm{m}$ to $1 \mathrm{~mm}$ ), which are deposited on the sea floor following meteorite showers. They are similar in density to sediment particles, but their rounded shape and transparent glassy appearance make them easy to distinguish and count under a dissecting microscope. Because their input to the sediment column is restricted in time, their subsequent vertical concentration profiles result from a balance between sediment reworking and sedimentation following the event (Glass et al. 1973). For example, microtektites derived from a meteorite encounter that occurred 700000 yr ago have been used to infer sediment reworking in the deep Indian Ocean (Glass 1969, Glass et al. 1973). As for other exotic particles, the specific properties (shape, structure and chemical composition) of microtektites may modify their mixing behaviour compared to ambient sediment particles (Wheatcroft et al. 1994).

Pollen grains. Davis (1974) used pollen grains as a tracer to investigate the feeding and particle transport of tubificids inhabiting deep lake sediments. Specific pollen taxa (size range 20 to $120 \mu \mathrm{m}$ ) were selected based on their absence (or rareness) in the natural sediment and/or for specific features that make them easily recognizable. The use of pollen grains proved valuable to study feeding behaviour (e.g. depth of feeding, size of ingested particles, etc.), as well as vertical changes in particle transport. However, the approach also has several drawbacks: (1) identification and counting are tedious and time consuming, (2) pollen grains may be preferentially selected by organisms during feeding and (3) relatively rapid decomposition of the pollen particle (up to $30 \%$ after 260 d) leads to an underestimation of the rate of particle transport.

\section{Deliberately introduced tracers}

Deliberately introduced tracers have been used both in situ and in the laboratory to assess the effects of environmental factors on sediment reworking (Gérino et al. 1994, Mugnai et al. 2003, Ouellette et al. 2004). Their main advantage is that they allow a direct quantification of sediment reworking over short temporal scales after the input of a tracer pulse at the sediment surface. However, the addition of deliberate tracers inevitably changes sediment conditions and thus could affect organism behaviour and sediment reworking.

Heavy mineral sand tracer. D'Andrea et al. (2004) used heavy mineral sand (garnet and magnetite) as particle tracers to assess sediment reworking in coarse sediments. Although this inert tracer could be suitable in sandy sediments, artefacts in the measurement of sediment reworking rates can nevertheless occur, since density significantly affects particle handling by benthic infauna (Jumars et al. 1982).

Isotopically labelled sediment particles. Natural sediment particles can be labelled with radioisotopic elements, classically ${ }^{137} \mathrm{Cs}$ (White et al. 1987) and ${ }^{51} \mathrm{Cr}$ (Hansen et al. 1999, Sandnes et al. 2000a,b). The vertical distribution of the tracer is monitored over time, and sediment reworking rates are calculated. This approach allows the assessment of short-term changes in sediment reworking.

Isotopically labelled organic matter. This method consists in labelling algae with ${ }^{13} \mathrm{C}$ or ${ }^{14} \mathrm{C}$ (Blair et al. 1996) and then assessing the vertical profile of these labels. As reported for chl $a$, bulk sediment reworking may be significantly overestimated because of the selectivity of organic-rich particles by benthic infauna (Taghon 1982, Lopez \& Levington 1987).

Metal doped sediment particles. This technique is based on the thermal diffusion of noble metals (typically $\mathrm{Au}$ and Ag, which are naturally present only in trace amounts) into the mineral matrix of sediments (Wheatcroft et al. 1994). The technique does not affect the size and surface properties of sediment particles and only has a slight $(<8 \%)$ effect on their density (Olmez et al. 1994). One limitation is the possible desorption in pore water and subsequent re-adsorption. However, such processes have not been detected during experiments (Olmez et al. 1994).

Glass beads. Glass beads with a size representative of the average sediment grain size are also used as particle tracers (Shull \& Yasuda 2001). In this sense, the method is similar to the microtektite method, but allows for short-term assessment of contemporary sediment reworking. The main shortcoming results from the exotic nature of the tracers, which have different surface properties from those of ambient sediment particles. These differences can be alleviated to some extent by the development of a biofilm on the surface of the beads prior to the experiments (Berg et al. 2001).

Microtaggants, luminophores and microspheres. Wheatcroft (1991) introduced the use of microtaggants, inert and non-toxic rough plastic particles with a size range of 50 to $125 \mu \mathrm{m}$ and a specific gravity of 1.4 (similar to natural sediment particles). To facilitate their recovery, they are coated with blue paint, which makes microtaggants similar to luminophores (see below).

Mahaut \& Graf (1987) introduced the use of luminophores. Luminophores are natural sediment particles that have been coated with a thin layer of UV fluorescent paint. Diameters of luminophores typically range between 10 and $500 \mu \mathrm{m}$, with a density of about $2.5 \mathrm{~g} \mathrm{~cm}^{-3}$. Microspheres are UV fluorescent balls of polystyrene divinylbenzene or latex that have a much smaller size (down to $1 \mu \mathrm{m}$ ) and lower density (e.g. $1.05 \mathrm{~g} \mathrm{~cm}^{-3}$ for polystyrene microspheres) than luminophores (Gielazyn 
et al. 1999, Ciutat et al. 2005). Because of their specific properties, the addition of microspheres does not modify initial sedimentary conditions. Their use is particularly interesting to investigate sediment reworking processes resulting mainly from feeding activity, since microspheres can be ingested together with surrounding sediment, and not on their own, even by the smallest species (Ciutat et al. 2005).

Usually, luminophore particles and microspheres are visually counted under a microscope, which can be tedious and time consuming (Mahaut \& Graf 1987, Gérino 1990, François et al. 1999, Ciutat et al. 2005, Fernandes et al. 2006). However, image analysis techniques have been recently introduced to facilitate this operation (Gilbert et al. 2003, Solan et al. 2004, Maire et al. 2006). As for other exotic particles, some doubts remain as to whether some of the properties (size, density and fluorescent paint) may bias the assessment of sediment reworking due to differential manipulations by benthic infauna. It has also been reported that the coating may fill micro-crevices, which are important for bacterial attachment (Wheatcroft et al. 1994).

\section{Particle-tracer recovery methods}

The standard method for assessing the vertical distribution of particle tracers within the sediment column consists in collecting and slicing a sediment core, and, subsequently, quantifying the tracer within each sediment layer (Table 3). This procedure has been used in situ and ex situ with both natural (e.g. radionuclides) and deliberate (e.g. luminophores) tracers, either under steady-state (typically for natural radionuclides) or non-steady-state conditions (when the tracer is introduced as a pulse at the sediment surface) (Cochran \& Aller 1979, Gérino et al. 1998, Turnewitsch et al. 2000, François et al. 2002, Mugnai et al. 2003, Schmidt et al. 2007). The thickness of each sediment layer is usually chosen between 0.5 and $1 \mathrm{~cm}$ in the upper most centimetres, and thereafter typically increases with depth. The amount of tracer within each sediment layer is estimated using a variety of techniques. Radionuclides and isotopically labelled particles are usually quantified using alpha or gamma spectrometry (Goldberg \& Koide 1962, Thomson et al. 2000, Schmidt et al. 2007), while metal-doped sediment particles are analyzed using instrumentation neutron activation analysis (Wheatcroft et al. 1994, Olmez et al. 1994), and chl a using HPLC (Sun et al. 1991, Gérino et al. 1998). All visually distinguishable tracers, such as microtektites, glass beads, microtaggants and luminophores, are either classically counted under a dissecting microscope (Glass et al. 1973, Wheatcroft 1991, Blair et al. 1996, Madsen et al. 1997, Fernandes et al. 2006), or

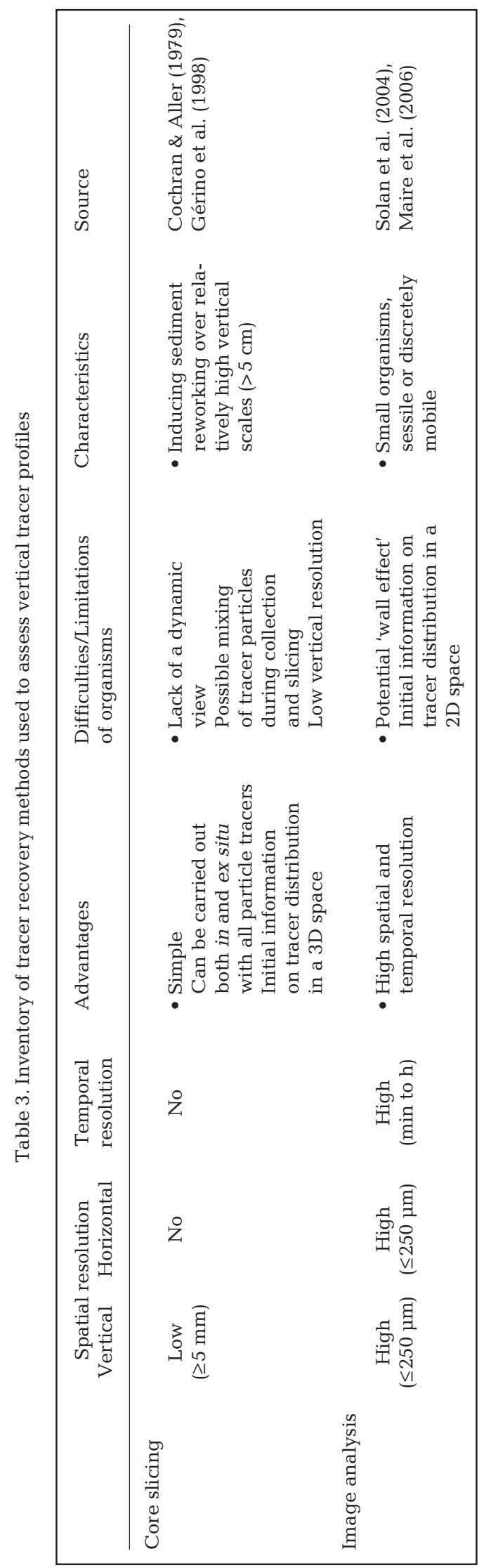


quantified using automated image acquisition and analysis techniques (Gilbert et al. 2003, Solan et al. 2004, Maire et al. 2006). The quantification of particle tracers within the sediment column can become difficult when their distribution is patchy or when the concentration approaches the detection limit. Overall, vertical profiles of radionuclides are widely used because of the sensitivity of the analytical method. Fornes et al. (2001), however, reported that the detection of shortlived radionuclides becomes difficult when the experimental duration approaches 5 times their half-lives.

Classical core slicing has several disadvantages including (1) lack of any dynamic view of sediment reworking, since cores are destroyed when assessing tracer profiles; (2) vertical resolution of tracer profiles is limited by the thickness of each sediment slice; (3) inability to assess sediment reworking at a spatial scale smaller than the whole experimental core (each slice is horizontally averaged); (4) possible mixing and carry-over between adjacent sediment layers during collection and slicing; and (5) no information about lateral particle transport. Methods using transparent thin aquaria or sediment profile imaging (SPI), combined with time-lapse photography, luminophore pulses and automated image analysis techniques, were recently introduced to overcome these drawbacks (Table 3). They result in high-frequency monitoring of luminophore displacements within a vertical plane of the sediment column. Using these approaches, Gilbert et al. (2003) and Solan et al. (2004) studied sediment reworking induced by natural benthic communities of the Swedish west coast, whereas Maire et al. (2006, 2007a) assessed the effects of food availability and temperature on sediment reworking by 2 closely related bivalves under laboratory conditions. A limitation of SPI and thin aquaria are potential wall effects. However, comparative measurements for thin aquaria showed that vertical tracer profiles derived from image analysis and classical slicing were similar (Maire et al. 2006). To our knowledge, this potential artefact has never been tested during in situ sediment profile imaging deployment. Moreover, as reported by Solan et al. (2004), SPI may induce an underestimation of sediment reworking, since some luminophores may be horizontally displaced away from the monitored sediment area.

\section{Modelling}

Types of sediment reworking models

There are 2 fundamental levels at which sediment reworking can be studied: the microscopic level of individual particles and the macroscopic level of the bulk sediment. These 2 levels have separate types of associated models. At the microscopic level, individual particles are displaced in discrete mixing events caused by various animal-sediment interactions, such as burrowing, ingestion/egestion, biodeposition and locomotion by epifauna (Solan \& Wigham 2005). Accordingly, models at this level need to 'track' the trajectories of individual particles. Although the motion of each sediment particle is intrinsically deterministic, the interplay between particles and biological activity may be considered sufficiently complex, so that a particle's motion can be described as a stochastic process. The associated type of model is a random-walk model, which describes particle displacement in terms of consecutive random sediment reworking events. When an organism moves in the sediment, reshuffling of the sediment occurs, and particles are dislocated to a new position. In recent years, random walk models have gained considerable interest in sediment reworking theory, but mostly from a theoretical perspective (Boudreau 1989, Wheatcroft et al. 1990, Meysman et al. 2003, Meile \& van Cappellen 2005).

One serious obstacle of random walk models is that they cannot be properly validated. This is because, with present experimental methods, it is not possible to track individual sediment particles. Moreover, the real interest of the sediment biogeochemist is to analyze tracer concentration profiles, which essentially characterize the 'averaged' behaviour of sediment particles. Accordingly, the relevant level of description is not that of the individual particle, but the macroscopic level of the sediment. The macroscopic models are termed continuum models, which describe how the concentration of tracer particles changes with time. Here, our prime interest is to discuss suitable tools for the analysis of tracer profiles, and, hence, only continuum models are further discussed; more details on random-walk models and their link to continuum models can be found in Meysman et al. (2003).

Two main types of continuum models are in use at present: (1) Local models are considered suitable to describe 'local transport', which includes sediment displacements that are spatially random, sufficiently frequent and occur over small spatial scales (Boudreau 1986a). (2) Non-local sediment reworking models are used for transport processes that lead to particle displacements between distant points or to directional transport of particles (Boudreau \& Imboden 1987).

Biodiffusion model (local mixing)

The most widely implemented particle dispersal model is the biodiffusion model, which assumes that Ficks' law of diffusion is applicable and which de- 
scribes particle dispersal by analogy with the diffusive heat transport (Goldberg \& Koide 1962, Guinasso \& Schink 1975, Meysman et al. 2003). If we consider vertical mixing over a depth layer of thickness $L$, the governing tracer equation becomes:

$$
\frac{\partial C}{\partial t}=D_{\mathrm{b}} \frac{\partial^{2} C}{\partial x^{2}}-\omega \frac{\partial C}{\partial x}-\lambda C
$$

where $x$ represents the depth into the sediment, $C$ is the concentration or activity of the selected tracer, $D_{\mathrm{b}}$ is the biodiffusion coefficient, $\omega$ is the burial velocity, $t$ is time and $\lambda$ the decay constant of the tracer.

In Eq. (3), the parameters $D_{\mathrm{b}}$ and $\omega$ are assumed not to depend on depth. Implicitly, Eq. (3) also requires that the porosity $(\phi)$ is constant with depth. Accordingly, this term drops from Eq. (3). The validity of these assumptions is discussed below. Suitable solutions of Eq. (3) are fitted to tracer depth profiles, and an optimal estimate for the biodiffusion coefficient $D_{\mathrm{b}}$ is obtained. For reactive tracers, $D_{\mathrm{b}}$ is typically deduced from the steady-state solution (Boudreau 1997):

$$
C(x)=C_{0} \exp \left(\frac{\omega-\sqrt{\omega^{2}+4 D_{\mathrm{b}} \lambda}}{2 D_{\mathrm{b}}} x\right)
$$

where $C_{0}$ is the activity or concentration of the tracer at the sediment-water interface and $\lambda$ is the decay constant of the tracer. To retain only $C_{0}$ and $D_{\mathrm{b}}$ as fitting parameters, suitable values of the burial velocity $\omega$ and the decay constant $\lambda$ should be known a priori. In sedimentary environments dominated by sediment reworking (i.e. $\omega L / D_{\mathrm{b}} \ll 1$ ), the advective term $(\omega)$ in Eq. (3) can be neglected. In other cases, $\omega$ should be independently determined, for example, by using the part of the tracer profile located just beneath the bioturbated layer that is unaffected by sediment reworking. A similar argument holds for the decay constant $\lambda$. Radioisotopes are popular tracers since their decay is tightly constrained (e.g. Crusius \& Kenna 2007, Lecroart et al. 2007a). In the case of chl $a$, the decay constant is less well constrained, and should be introduced as an additional unknown parameter (e.g. Gérino et al. 1998). Fitting 2 parameters $\left(D_{\mathrm{b}}, \lambda\right)$ to a single tracer profile rather than one $\left(D_{\mathrm{b}}\right)$, however, introduces considerable uncertainty (see below).

For conservative tracers, $D_{\mathrm{b}}$ is typically deduced from the transient solution for an idealized pulse initial condition (Guinasso \& Schink 1975). This pulse is an idealization of a unit layer of tracer particles added to the sediment-water interface. With the assumption of negligible burial velocity, this solution becomes:

$$
C(x, t)=\frac{1}{\sqrt{\pi D_{\mathrm{b}} t}} \exp \left(\frac{-x^{2}}{4 D_{\mathrm{b}} t}\right)
$$

In this case, $C(x, t)$ represents the normalized tracer concentration relative to the initial input introduced at the sediment-water interface. This method has been applied to microtektites (e.g. Guinasso \& Schink 1975) and luminophores (e.g. Gérino et al. 1998).

\section{Non-local mixing}

Non-local models are typically invoked when particular features in tracer profiles appear that cannot be explained by the classical biodiffusion analogy (Boudreau 1986b, Boudreau \& Imboden 1987, Soetaert et al. 1996, François et al. 2002). For example, the presence of subsurface maxima in radiotracer profiles cannot be reproduced with the biodiffusion model (Soetaert et al. 1996, Shull 2001, Delmotte et al. 2007). Different modes of non-local transport have been described in the literature: upward conveyor, downward conveyor, regenerator and gallery diffusor (Fisher et al. 1980, Boudreau 1986b, Rice 1986, Robbins 1986, Smith et al. 1986, Soetaert et al. 1996, François et al. 1997, 2002). These reworking mechanisms correspond to different functional groups within macrobenthic communities (François et al. 1997). Note that non-local transport can be the dominant process in marine sediments. Along the ocean margin exchange (OMEX) transect, Soetaert et al. (1996) showed that between 8 and $86 \%$ of the total flux of radionuclides enters the sediment by non-local exchange.

Until now, non-local models have been 1-dimensional (1D) descriptions, except for the 2D models developed by François et al. (2001, 2002), which also incorporated lateral tracer transport. Up to now, 2D models have never been validated, due to the lack of appropriate experimental data.

Moreover, all non-local reworking mechanisms can be captured by the general non-local exchange formalism (Boudreau \& Imboden 1987, Boudreau 1997, Meysman et al. 2003):

$$
\frac{\partial C}{\partial t}=\int_{0}^{L} K\left(x, x^{\prime} ; t\right) C\left(x^{\prime}, t\right) \mathrm{d} x^{\prime}-\int_{0}^{L} K\left(x^{\prime}, x ; t\right) C(x, t) \mathrm{d} x^{\prime}
$$

where $K\left(x, x^{\prime}\right)$ represents the exchange function and $L$ is the depth of the (bioturbed) sediment layer. The 2 integral terms on the right-hand side describe the exchange between non-adjacent depth layers (they, respectively, represent the supply and removal of tracer from the depth layer centred at position $x$ ). These 2 terms are basically sink and source terms that need specification for different sediment environments. In other words, for each mode of non-local reworking, the exchange function $K$ requires a suitable and explicit mathematical form.

In general, the exchange function $K$ will be a function of a number of parameters. Like the biodiffusion coefficient, these parameters need adjustment when 
fitting the non-local model solutions to the observed tracer profiles (Soetaert et al. 1996, François et al. 2002). This is often a challenging task, because nonlocal models are generally complex: they incorporate far more parameters than the single $D_{\mathrm{b}}$ of the biodiffusion model. The synchronous calibration of multiple parameters is numerically demanding and requires customized software, while fitted parameters often are poorly constrained (i.e. they have a large uncertainty associated). Accordingly, recent research efforts have focused on how to optimize model complexity (Meysman et al. 2006, Delmotte et al. 2007), and how to rigorously assess the uncertainty associated with calibrated parameters (Anderson et al. 2006). There are a number of ways to reduce model complexity by decreasing the number of calibrated model parameters. One way is to constrain parameter values a priori based on literature information. Another way is to use core imaging techniques to characterize parameters (Shull 2001), or to perform experiments with multiple tracers and sequentially calibrate parameters. See, for example, Delmotte et al. (2007) for a detailed case study of how to systematically constrain parameters in a model that describes head-down deposit feeding of tubificid oligochaetes.

\section{Lattice-automaton sediment reworking models}

Experimental techniques in sediment reworking research are frustrating in that they cannot address interactions between organisms and sediment at the microscale. For example, it is not possible to tag individual particles and follow their trajectories through the sediment. A new modelling approach developed by Choi et al. (2002) overcomes these problems. It is called lattice automaton bioturbation simulation (LABS), and basically constitutes a computer emulation of an actual sediment environment. In essence, LABS is composed of a 2D matrix of pixels, which can be designated as sediment particles, porewater, or organisms. Organisms move through the lattice as programmable entities, i.e. automatons, and follow certain rules that define organism displacement, particle ingestion, size and density distribution. These rules are designed to mimic the behaviour of benthic organisms such as subsurface deposit feeders. The activity of the virtual organisms (moving, feeding, burrowing, etc.) then creates particle dispersal. This allows all types of numerical sediment reworking simulations. For example, sediment particles can be virtually tagged with radioactive tracers of different half-lives (Boudreau et al. 2001, Reed et al. 2006). LABS is not a sediment reworking model in the sense of the previously discussed biodiffusion and non-local models. Rather than analyzing data, LABS is designed to generate synthetic tracer data. For example, the 2D distribution of the tracer particles within LABS can be laterally integrated, which results in $1 \mathrm{D}$ tracer profiles. These profiles can be subsequently analyzed by the classical models, i.e. the biodiffusion or non-local models discussed above. Accordingly, the purpose of LABS is not to replace existing models, but rather to provide a tool to investigate sediment reworking at the microscopic levels where data collection is impossible with current experimental techniques. LABS simulations allow the establishment of links between organism behaviour and classical sediment reworking parameters (Boudreau et al. 2001). One topic of great importance is to test when and where the biodiffusion model can be used to analyze tracer profiles (Reed et al. 2006).

\section{DISCUSSION}

\section{Direct versus particle tracer methods}

Direct methods, based on the collection of sediment conveyed by benthic infauna to the sediment surface (i.e. direct collection, entrapment and levelling) clearly suffer from a lack of accuracy (see Table 1). They account only for that portion of sediment reworking that results in a transfer of sediment particles to the sediment-water interface. Accordingly, they only provide a rough qualitative estimate of the rate of sediment reworking. This explains why they have been progressively abandoned. The recent development of surface image analysis, and more importantly of laser telemetry, provide a new generation of techniques with the potential for significant improvement. These approaches are non-destructive and require no sediment collection, nor any modification of the sediment-water interface. In addition, laser telemetry accounts for both particle excavation (i.e. transport of sediment from the surface to deeper level) as well as accumulation at the sediment-water interface, and allows the assessment of sediment reworking with a high spatial (on the micrometre order) resolution. Overall, laser telemetry and, to a lesser extent, surface image analysis constitute the most promising direct approaches to infer sediment reworking, even though these new techniques still require further testing and development.

As opposed to direct methods, tracer methods are based on the analysis of vertical tracer concentration profiles within the sediment column. Consequently, these 2 approaches provide an insight into different aspects of sediment reworking. Direct methods can account for both horizontal and vertical sediment reworking, provided that particles end up at (or in the 
immediate vicinity of) the sediment-water interface. However, they do not allow a distinction between these 2 components. Conversely, particle-tracer methods assess only the vertical component of sediment reworking. The choice of a direct versus a particle-tracer method therefore depends on the mode of the sediment reworking, as well as the size, behaviour and position of the bioturbating organism (e.g. complexity of burrow structures). Direct methods can be appropriate for certain surface or sub-surface deposit feeders (Rowden et al. 1998, Hollertz \& Duchêne 2001, Lohrer et al. 2005), whereas particle-tracer methods are appropriate for organisms inducing strong vertical displacement of sediment particles (e.g. gallery biodiffusors, conveyor belt deposit feeders) (François et al. 2002, Caradec et al. 2004, Ouellette et al. 2004, Maire et al. 2006).

There are also important discrepancies in the way sediment reworking is assessed through direct and particle-tracer methods. These discrepancies are linked to the existence of a modelling step in the particle-tracer method that is not present in the direct methods. Direct methods result in an evaluation of the amount of sediment reworked per unit of time (i.e. analogous to a flow), whereas particle-tracer methods result in a sediment reworking rate (i.e. biodiffusion coefficient $\left[D_{\mathrm{b}}\right]$, step length squared divided by resting time), which is computed through modelling. This makes any comparison between the 2 kinds of methods difficult with respect to the relationship between biological activity and sediment reworking. Maire et al. (2007b) used both direct (surface image analysis) and particle-tracer methods (with a biodiffusion model) for the deposit-feeding bivalve Abra ovata. They found a tight relationship between direct observation of siphon activity and sediment reworking assessed by direct methods (laser telemetry). The relationship was less clear when sediment reworking was assessed through particle tracer methods (luminophores coupled with 2D image acquisition) because (1) there were several types of activity inducing different kinds of luminophore displacement and (2) there was no correlation between the temporal scales associated with the measurement of bivalve activity and the computation of $D_{\mathrm{b}}$. The choice between direct and particle tracer approaches, thus, also clearly relies on the ecological/biogeochemical question tackled.

\section{Tracer characteristics and inherent limitations}

As pointed out above, there is a large variety of particle tracer methods corresponding to different tracers and different tracer recovery methods. The choice of a particular tracer largely determines the time scale over which sediment reworking is assessed. The tracer re- covery method mainly controls the spatial domain (1D, 2D) over which sediment reworking is studied. Each particle tracer has its inherent limitations. Microtektites, for example, have been used to assess sediment reworking in the deep Indian Ocean (Glass 1969). However, the use of microtektites is tightly limited by the number of meteorite showers that produces them. Moreover, this tracer only provides information on reworking in the period immediately following the encounter and assumes that both sediment reworking and sedimentation rates are constant during that period.

$\mathrm{Chl} \mathrm{a}$ is not a tracer for mineral particles, but rather for the organic matter associated with these particles. $\mathrm{Chl} a$ is considered to be representative of the very labile fraction of sedimentary organic matter (Grémare et al. 1997). Therefore, its use as a tracer could be biased, because the quality of particulate organic matter affects biological processes involved in sediment reworking, most importantly feeding activity (Maire et al. 2006). This may explain why studies based on chl a typically result in higher sediment reworking rates than those based on radionuclides and luminophores (Gérino et al. 1998, Green et al. 2002). The same limitation applies to studies that use isotopically labelled organic matter (Blair et al. 1996). One way to overcome this selective-dispersal problem is to use natural sediment particles and label them with isotopes or metal. This method also leaves the density of particles unaltered relative to the bulk surrounding sediment. Isotope labelling and metal doping have, however, rarely been used (Olmez et al. 1994, Wheatcroft et al. 1994), possibly due to constraints in the preparation and analysis of the sediment. In contrast, the use of exotic particles such as luminophores and microspheres is much more widespread (Gérino 1990, François et al. 1999, Solan et al. 2004, Mermillod-Blondin et al. 2005, Fernandes et al. 2006, Maire et al. 2006). Luminophores are at present the most often used exotic particles for assessing sediment reworking. The primary practical limitation is the time required to count them. This same limitation also holds for glass beads and microtaggants. However, recent progress in image analysis now allows the automated identification and counting of luminophores under UV light (Gilbert et al. 2003, Solan et al. 2004, Maire et al. 2006). The main disadvantage of luminophores concerns their ability to mimic natural sediment particles. Luminophores have no organic coating and are covered with a fluorescent paint, and the (negative) effects of this on feeding and ingestion are unknown. Avoidance effects may result in an underestimation of the particle transport. Radionuclides are preferentially associated with fine particles that preclude their use in sandy and coarse sediments, because of the differential transport of fine particles through porewater advection. The counting 
of radionuclides requires a substantial amount of sediment. The typical procedure involves the collection and slicing of sediment cores, which restrict the radionuclide approach to a $1 \mathrm{D}$ description of sediment reworking with a limited spatial resolution. Despite their respective drawbacks, luminophores and radionuclides are currently the most commonly employed tracers to quantify sediment reworking.

\section{Spatial assessment of sediment reworking}

A challenge in the study of sediment reworking is how to deal with spatial heterogeneity. As stated above, tracer methods have been mainly developed and applied to investigate the vertical (1D) component of sediment reworking. The standard approach to assess tracer concentration patterns remains core slicing. The homogenization of the tracer within each slice results in a smoothed vertical 1D profile, which helps to explain the 'biodiffusive paradox' (Maire et al. 2007a). Core slicing does not allow assessment of the horizontal component of sediment reworking, which requires the 2D mapping of particle tracer concentrations. Such 2D mappings have recently been achieved by using luminophores in combination with thin aquaria in the laboratory (Maire et al. 2006, 2007a,b) and sediment profile imagery of natural communities (Gilbert et al. 2003, Solan et al. 2004). However, no sediment reworking model has yet been applied to 2D sediment reworking. Maire et al. (2006) used a classic biodiffusive model to infer the horizontal heterogeneity of vertical sediment reworking and the influence of slice thickness on the computation of the sediment reworking rate. Gilbert et al. (2003) reduced the 2D luminophore distribution to a single sediment reworking coefficient (optical reworking coefficient) that encompasses both vertical and horizontal biological mixing. Wheatcroft (1991) applied a specific tracer injection method to calculate the horizontal component of the sediment reworking rate in situ.

From a methodological standpoint, a sound assessment of horizontal sediment reworking would require tracking of individual particle displacements. In spite of the technological advances in image analysis, this has not yet been achieved. One possibility is to increase image acquisition frequencies from $600 \mathrm{~s}$ (Maire et al. 2007b) to ca. 1 s (i.e. the current limit of sensors). Furthermore, the algorithm developed for the study of larval swimming (Duchêne \& Nozais 1994, Duchêne \& Queiroga 2001) and particle displacement along the tentacles of surface deposit feeders (Maire et al. 2007c) may prove efficient for tracking luminophores as well. Another possibility is to deposit luminophores in restricted areas rather than homogeneously spreading them over the entire experimental sediment surface. This way it would be possible to assess the horizontal component of their displacement from their original location. However, a fundamental obstacle is that the sediment matrix is not transparent, and image analysis can follow particles only within the 2D plane of the aquarium wall or SPI interface.

Ultimately, a full description of sediment reworking will have to be achieved in 3D. However, there is currently no method available for this purpose. Computerassisted tomography (CAT-scan) is used to describe the $3 \mathrm{D}$ distribution of biogenic structures in sediment (Mermillod-Blondin et al. 2003, Dufour et al. 2005, Rosenberg et al. 2007). This method measures the density of elementary (sediment) cells called voxels. It can be used as a tracer method, if the tracer particles are slightly different in density from the surrounding sediment (Rosenberg et al. 2008). This new approach is promising, but still presents 2 difficulties: (1) Selective dispersal, as density differences between the tracer and the surrounding sediment may affect sediment reworking (see above). (2) Resolution, as the size of each voxel is currently much larger than that of individual tracer particles. Therefore, the average density within a voxel may actually correspond to a combination of materials of very different densities (e.g. water, sediment, tracer particles). Rosenberg et al. (2008) tried to resolve this resolution problem when using aluminium as a tracer to study the sediment reworking of an Amphiura filiformis community. They proposed to consider that voxels with a density compatible with the presence of aluminium indeed corresponded to reworked aluminium only if they were connected to the sediment-water interface through a continuous series of water and/or aluminium voxels (i.e. if those voxels were in direct contact with a biogenic structure). Rosenberg et al. (2007) recommended a similar criterion for the assessment of biogenic water. Nevertheless, this approach does not account for tracer particles that have been reworked away from biogenic structures, and its applicability is restricted to certain types of sediment reworking. More straightforward ways to resolve the difficulty could simply consist of using a higher resolution (but this increases the scan time substantially), and/or a different type of CAT based on radioisotope measurement (PET-scan).

\section{Validity of the biodiffusion model}

Modelling of particle tracer profiles, and the issue as to whether biodiffusion can appropriately model tracer profiles already have a relatively long history in sediment reworking research (Boudreau 1986a, Meysman et al. 2003, Reed et al. 2006). There are 2 basic aspects 
to the problem: (1) is the biodiffusion equation (Eq. 3) applicable? (2) Are the assumptions (constant tracer flux, constant parameters, etc.) in the typical application of Eq. (3) justified?

The validity of the biodiffusion model has been the subject of a number of theoretical studies (Boudreau 1986a, Boudreau \& Imboden 1987, Meysman et al. 2003). The picture that emerges from these is that validity of the biodiffusion model rests on a comparison of 2 different types of scales: (1) the inherent time and length scales of sediment reworking (i.e. the distance over which particles are displaced and the frequency of these displacement events); (2) the length scale and time scale of observation. For radioisotopes, this observational length scale can be interpreted as the depth of tracer penetration, and the observational time scale is the half-life of the radioisotope (5 times the half-life determines the time window of experimental observation). Meysman et al. (2003) concluded that the biodiffusion analogy can be theoretically justified when the intrinsic time and length scales of sediment reworking are much smaller than their observational counterparts. Yet, when scrutinizing natural sediment reworking activity, these authors conclude that these conditions are often not satisfied, particularly for experiments over short time scales (e.g. short-lived radioisotopes, chl a studies, pulse-tracer experiments with luminophores). This is because particles can be displaced over the same centimetre scale distance as the tracer penetration depth; moreover, the time between particle displacements becomes large when compared to the observational time scale. Therefore, Meysman et al. (2003) concluded that in many cases, the application of the biodiffusion model is questionable from a theoretical point of view. Still, in practice, tracer profiles often look diffusive, and the biodiffusion analogy is widely employed to analyze these profiles. Meysman et al. (2003) refer to this apparently contradictory situation as the 'biodiffusion paradox'.

Boudreau \& Imboden (1987) have proven that the biodiffusion model can be deduced from the integrodifferential equation of the non-local exchange model when particle exchange is symmetric and operates on a small scale (see also Meysman et al. 2003). Consequently, the non-local exchange model emerges as the more general formalism, which covers all modes of biological mixing. The biodiffusion paradox could be resolved if we better understood the exact conditions under which the more general model leads to the biodiffusion model. This is an important topic for future research (see for example Meysman et al. 2008, this Theme Section).

A second puzzling observation is that the biodiffusion coefficient deduced from radioisotope profiles seems to be dependent on the half-life of the tracer.
Smith et al. (1993) and Pope et al. (1996) have examined the mixing intensity from radioisotopes with different half-lives. They concluded that, in many deepsea sediments, the biodiffusion coefficients derived from short-lived tracers are much higher than those derived from long-lived ones. They suggested that this age-dependent mixing results from selective ingestion and, thus, mixing of recently deposited food-rich particles. The occurrence of age-dependent mixing driven by food quality is supported by field measurements (e.g. gut enrichment of short-lived tracers) and particle introduction experiments (Smith et al. 1993, Miller et al. 2000, Fornes et al. 2001). As an alternative to agedependent mixing, it has also been suggested that tracer dependence of the biodiffusion coefficient can simply result from unjustified assumptions of the biodiffusive model. The biodiffusion analogy indeed requires that the number of mixing events experienced by each sediment particle needs to be $>25$ (Boudreau 1986a, Meysman et al. 2008). Based on LABS simulation, Reed et al. (2006) confirmed that short-lived radioisotopes are likely to provide biased estimations of the biodiffusion coefficient in sedimentary environments characterized by low sediment reworking. On the other hand, Maire et al. (2007a) experimentally determined the step length and resting time for the deposit-feeding bivalve Abra ovata at field densities, and the results suggest that the assumptions of the biodiffusion model can be met in littoral environments where sediment reworking is high. A future challenge, therefore, consists in identifying which part of the observed tracer-dependent mixing is explained by age-dependent mixing and/or by unjustified assumptions of the biodiffusion model.

The above theoretical considerations reveal that the conditions for the biodiffusion analogy to hold depend on the tracer: particles must be sufficiently frequently displaced within the time window of the specific tracer. This implies that some forms of sediment reworking can be seen as 'local' with respect to long-lived radioisotopes and considered 'non-local' with respect to short-lived ones. This implies that for the same type of sediment reworking activity, different models may be needed at different time scales. Maire et al. (2007a) showed experimentally that sediment reworking displayed non-local features during the first $48 \mathrm{~h}$ of an experiment and subsequently evolved in biodiffusive mixing. This result confirms the theoretical predictions that over short time scales the non-local model should provide a more accurate description of sediment reworking, but as the number of sediment reworking events increases, the non-local model should converge toward the biodiffusion model (Meysman et al. 2008).

In conclusion, the biodiffusion model offers a simple mathematical formalism for the interpretation of tracer 
profiles, and, therefore, it constitutes an attractive way to quantify biological mixing. Nonetheless, one should be cautious when applying the biodiffusion model. Non-local models are particularly relevant for short time scale investigations, and also for benthic fauna that display a clear non-local transport activity (e.g. head-down deposit feeders) and thus generate particular tracer profile shapes (e.g. subsurface maxima).

\section{Temporal assessment of sediment reworking}

It is important to define the time scale at which sediment reworking is considered, taking into consideration the objectives of the study and the type of particle tracer. For example, the term 'short time scale' is currently used for radionuclide experiments that span from one to several months (Gérino et al. 1998, Schmidt et al. 2007). However, the term 'short time scale' is also used for tracer experiments with luminophores that last $<1 \mathrm{~d}$ or even $<1 \mathrm{~h}$ (Solan et al. 2004, Maire et al. 2006, 2007a,b). Each tracer indeed provides information about sediment reworking over a different time scale, depending on its reactivity.

Non-conservative tracers, such as radionuclides and chl $a$, exhibit an exponential decay with time (and thus with depth in undisturbed sediment). In environments with low sedimentation rates, chl a (half-life between 3 and $250 \mathrm{~d}$ ) and radionuclides with short half-lives, such as ${ }^{234} \mathrm{Th}(24.1 \mathrm{~d})$ and ${ }^{7} \mathrm{Be}(53.4 \mathrm{~d})$, should thus theoretically be present only near the sediment surface. Therefore, their penetration to deeper sediment layers is indicative of vertical sediment reworking. Analysis of steady-state tracer profiles allows the estimation of sediment reworking rates over different periods of time and depends on their decay kinetics. ${ }^{210} \mathrm{~Pb}(22.3 \mathrm{yr})$ is particularly appropriate to assess the depth of the reworked sediment layer, and is suitable to estimate the average accumulation rate and sediment reworking rate over the past $100 \mathrm{yr}$. Therefore, ${ }^{210} \mathrm{~Pb}$ has often been used to assess sediment reworking in the deep sea (Peng et al. 1979, Stordal et al. 1985, Thomson et al. 1988, 2000, Soetaert et al. 1996, Hughes et al. 2005). Conversely, chl $a,{ }^{234} \mathrm{Th}$ and ${ }^{7} \mathrm{Be}$ are more appropriate to derive information about sediment processes occurring at a seasonal time scale (i.e. 3 to $4 \mathrm{mo}$ ) (Aller \& Cochran 1976, Fuller et al. 1999, Schmidt et al. 2007). These short time tracers have also been used to assess biogenic sediment reworking in more intensively reworked sediments such as shallow coastal environments (Aller \& Cochran 1976, Rice 1986, Lecroart et al. 2005). One disadvantage of chl $a_{1}$ compared to radionuclides, is that its degradation rate is highly dependent on environmental conditions (Sun et al. 1993).
Sediment reworking experiments usually involve naturally occurring tracers (radionuclides and chl a), based on the assumption that a constant flux of tracer arrives at the sediment surface. This may seem surprising, as many authors have concluded that transientstate regimes are the rule in aquatic sediments rather than the exception. Nonetheless, steady-state conditions form a model approximation. Therefore, the steady-state approximation remains valid when the fluctuations exhibit significantly shorter or longer periodicity than the observational time scale. If this is the case, a sedimentary system can still be described by a steady-state model (Boudreau 1997). The real problem is when the fluctuations have about the same time scale as the observational time scale. When using short-lived radioisotopes like ${ }^{7} \mathrm{Be}$ (half-life $53.4 \mathrm{~d}$ ) or ${ }^{234} \mathrm{Th}$ (half-life $24.1 \mathrm{~d}$ ), daily fluctuations of the deposition flux (e.g. resulting from tidal currents) will not be important, as they simply can be considered as noise superimposed on the constant average flux. Similarly, decadal changes in the flux of these tracers (e.g. resulting from climate change) will not hamper the steadystate assumption of the model. However, seasonal fluctuations are on the same time scale as the tracers, and transient effects can occur in the calculation of the reworking rate. Lecroart et al. (2007b) showed that the presence of a seasonally changing flux regime can generate a significant error, up to a factor of 2 , in the rate $\left(D_{\mathrm{b}}\right)$ calculation. Moreover, radionuclide profiles associated with such a transient flux still adopt the exponential shape of the steady-state profiles. Consequently, transient regime effects are difficult to detect in field data, and, hence, it would be erroneous to justify the steady-state approximation by the simple observation of an exponential profile.

Radionuclides are undoubtedly useful tracers to measure and compare sediment reworking rates from different sites and over a relatively large range of time scales. However, variations in biogenic sediment reworking over very short temporal scales (on the order of hours or minutes), in relation with quick temporal changes of environmental parameters, cannot be evaluated using only radionuclides as particle tracers. This is particularly restricting, since one of the main effects of sediment reworking is precisely its influence on organic matter mineralization, a process that may be affected by short-term sediment reworking events, depending on the type of organic matter. Moreover, several studies have shown that sediment reworking modes depend on the type of activities (e.g. feeding mode) and that these modes can change over short time scales, in phase with environmental factors such as food availability and temperature. It is thus mandatory to obtain information on the time scale of sediment reworking events. Only the use of a pulse of conserva- 
tive tracers at the sediment-water interface, together with high-frequency image analysis techniques, can document such rapid mixing events. This approach also allows the identification of modes of sediment reworking and the assessment of rapid temporal changes in sediment reworking rates in relation to environmental parameters. However, care should be taken when analysing tracer profiles, since the tracer particles may initially settle into burrows, tubes, or pits in the sediment column during the spreading procedure. This can generate subsurface peaks, which are usually considered the hallmark of non-local transport.

\section{Temporal variation of biodiffusion $D_{\mathrm{b}}$}

Seasonal changes in environmental conditions are commonly observed in temperate areas, and are especially pronounced in shallow environments such as Mediterranean lagoons, where the yearly amplitude of temperature can reach $25^{\circ} \mathrm{C}$. Such seasonal changes can induce a seasonal pattern in the activity of the lagoon's benthic fauna, and hence the reworking rate, as recently suggested by Schmidt et al. (2007). Using a modelling approach, Lecroart et al. (2007a) showed that the biodiffusion model is suitable to quantify the seasonal variability of particle mixing activities, provided that radioisotopes are used that have a half-live lower than the length of the season (e.g. ${ }^{224} \mathrm{Th}$ and ${ }^{7} \mathrm{Be}$ ). For such short-lived radioisotopes, the tracer profiles are rapidly adjusted to the new reworking conditions and the classical procedure to estimate $D_{\mathrm{b}}$ can be used. Recently, Maire et al. (2007a) investigated seasonal variations of the mixing activity based on pulse-tracer experiments with luminophores. They concluded that both temperature and food availability have an impact on sediment reworking during summertime, whereas temperature and not food availability controls sediment reworking during wintertime. Conversely, based on 3 yr time series measurements, Wheatcroft (2006) reported no significant control of the temperature on sediment reworking rates at a site where temperature seasonally varies between 7 and $12^{\circ} \mathrm{C}$, whereas a significant variation in food availability between seasons was hypothesized. However, Wheatcroft (2006) underlined that temporal changes in sediment reworking rates that result from both biotic (e.g. organism abundance, size) and abiotic parameters (e.g. temperature, food availability) are particularly difficult to assess during in situ experiments. These parameters can vary simultaneously and affect sediment reworking in different ways, e.g. decrease of temperature during a time of increasing animal abundance and food availability (Wheatcroft 2006).

\section{Depth variation of porosity, burial velocity and $D_{\mathrm{b}}$}

The conventional procedure to estimate $D_{\mathrm{b}}$ from tracer profiles typically assumes that the parameters $\left(D_{\mathrm{b}}, \omega, \phi\right)$ in Eq. (3) do not vary with depth. Note that under the assumption of steady-state compaction, the porosity $\phi$ and the burial velocity $\omega$ will co-vary with depth, as mass conservation requires that the product $(1-\phi) \omega$ remains constant. Meysman et al. (2007) tested how strongly the constant-porosity assumption could affect the resulting $D_{\mathrm{b}}$ estimates. They showed that the influence of porosity gradients on $D_{\mathrm{b}}$ values was modest. Also note that in most sedimentary environments, sediment reworking rates are much higher than sedimentation rates, and, hence, $D_{\mathrm{b}}$ calculation will not be affected by variations in the burial velocity.

Boudreau (1986a) explored the influence of a depthdependent $D_{\mathrm{b}}$ on the shape of tracer profiles. This study concluded that for steady-state profile of radio-tracers, depth-dependent $D_{\mathrm{b}}$ and constant $D_{\mathrm{b}}$ models could generate very similar profiles. Differences occur if $D_{\mathrm{b}}$ decreases faster than according to quadratic decay, and only when $\omega L / D_{\mathrm{b}}(0) \leq 1$ and $0.03 \leq \lambda L^{2} D_{\mathrm{b}}(0) \leq 3$. In the transient case, when simulating the pulse input of an inert tracer, the depth-dependent $D_{\mathrm{b}}$ and the constant $D_{\mathrm{b}}$ cases could also have similar profiles. Consequently, the depth dependence of the biodiffusion coefficient cannot be constrained from a single tracer profile (Boudreau 1986a). Some biogeochemical sediment models introduce a transition zone between an upper bioturbated layer (with constant $D_{\mathrm{b}}$ ) and a deeper burial zone (where $D_{\mathrm{b}}=0$ ). In this transition zone, $D_{\mathrm{b}}$ decreases with depth (e.g. Rabouille \& Gaillard 1991, van Cappellen \& Wang 1996, Berg et al. 2003). This smooth transition is advantageous from a numerical perspective (discontinuities are to be avoided in numerical solution procedures), but the exact mathematical form of this depth dependence is poorly constrained by data.

\section{CONCLUSIONS}

Many methods are available to measure sediment reworking, each of them has advantages and drawbacks. Amongst the direct methods, laser telemetry is the most promising, since it allows for an accurate measurement of sediment reworking at the sediment-water interface, with relatively high spatial and temporal resolutions. Moreover, this method can be improved by decreasing the time required to capture successive micro-topography mappings. Amongst the tracer methods, the use of natural radionuclides in combination with classical core slicing techniques is a solid and proven technique that is here to stay. However, attention must be given to the tracer dependence of 
reworking rates, and further studies should focus on the exact mechanism behind this tracer dependence. In addition, the use of conservative tracers (e.g. luminophores) supplied at the sediment-water interface under non-steady-state conditions has received a lot of attention. This technique is particularly promising when used in combination with sediment imaging profiling and cutting edge image analysis techniques that allow for a high-resolution assessment of short-term temporal and spatial changes in 2 dimensions. This approach also allows for the simultaneous measurement of biological activity and sediment reworking. Accordingly, it can be used to relate changes in the rate of sediment reworking with specific variations in infaunal activity (Solan et al. 2004, Maire et al. 2007b). Such information is particularly needed for a better conceptualization of sediment reworking models, and thus for a better quantification of sediment reworking.

With regard to the modelling of sediment reworking, several topics can be identified for future research. Particular efforts need to be addressed to better understand the exact conditions under which the different models can be used with the available tracers. Furthermore, a model is by definition a simplified representation of reality, but there is a trend towards the development of more and more complex models. This then brings on the issue of simplicity versus complexity: What is the optimal complexity of a model to explain certain features of tracer concentration patterns? Further breakthrough developments are expected from LABS simulations, when more complex biological behaviour is incorporated, such as particle selectivity. All these topics require close cooperation between modellers and experimental biologists.

Overall, no method can currently be considered as standard. Instead, the selection of a method depends on the problem at hand and the type of environment investigated (deep sea versus coast). It is thus mandatory to first define the scientific objectives and requirements before selecting the most appropriate method, which may itself include several complementary approaches (e.g. laser telemetry, thin aquaria and luminophores; see Maire et al. 2007b) or require a further development of existing methods.

Acknowledgements. We thank 3 anonymous reviewers for their detailed and constructive comments. F.M. was supported by an Odysseus grant from the Research Foundation Flanders.

\section{LITERATURE CITED}

Abele-Oeschger D, Theede H (1991) Digestion of algal pigments by the common periwinkle Littorina littorea L. (Gastropoda). J Exp Mar Biol Ecol 147:177-184

Aller RC (1982) The effects of macrobenthos on chemical properties of marine sediment and overlying water. In: McCall PL, Tevesz MJS (eds) Animal-sediment relations - the biogenic alteration of sediments. Topics in geobiology, Vol 2. Plenum Press, New York, p 53-102

- Aller RC, Cochran JK (1976) ${ }^{234} \mathrm{Th} /{ }^{238} \mathrm{U}$ disequilibrium in near-shore sediment: particle reworking and diagenetic time scales. Earth Planet Sci Lett 29:37-50

Andersson JH, Middelburg JJ, Soetaert K (2006) Identifiability and uncertainty analysis of bio-irrigation rates. J Mar Res 64:407-429

Bender K, Davis WR (1984) The effect of feeding by Yoldia limatula on bioturbation. Ophelia 23:91-100

Berg P, Rysgaard S, Funch P, Sejr MK (2001) Effects of bioturbation on solutes and solids in marine sediments. Aquat Microb Ecol 26:81-94

> Berg P, Rysgaard S, Thamdrup B (2003) Dynamic modeling of early diagenesis and nutrient cycling. A case study in an arctic marine sediment. Am J Sci 303:905-955

Berkenbusch K, Rowden AA (1999) Factors influencing sediment turnover by the burrowing ghost shrimp Callianassa filholi (Decapoda: Thalassinidea). J Exp Mar Biol Ecol 238: 283-292

Blair NE, Levin LA, DeMaster D, Plaia G (1996) The short term fate of fresh algal carbon in continental slope sediments. Limnol Oceanogr 41:1208-1219

Boudreau BP (1986a) Mathematics of tracer mixing in sediments. I. Spatially-dependent, diffusive mixing. Am J Sci 286:161-198

Boudreau BP (1986b) Mathematics of tracer mixing in sediments. II. Non-local mixing and biological conveyor-belt phenomena. Am J Sci 286:199-238

$>$ Boudreau B (1989) The diffusion and telegraph equations in diagenetic modelling. Geochim Cosmochim Acta 53: 1857-1866

Boudreau B (1997) Diagenetic models and their implementation: modelling, transport and reactions in aquatic sediments. Springer Verlag, Berlin

Boudreau BP, Imboden DM (1987) Mathematics of tracer mixing in sediments. III. The theory of nonlocal mixing within sediments. Am J Sci 287:693-719

> Boudreau BP, Choi J, Meysman F, Francois-Carcaillet F (2001) Diffusion in a lattice-automaton model of bioturbation by small deposit feeders. J Mar Res 59:749-768

Cadée GC (1976) Sediment reworking by Arenicola marina on tidal flats in the Dutch Wadden Sea. Neth J Sea Res 10: 440-460

Callender E, Robbins JA (1993) Transport and accumulation of radionuclides and stable elements in a Missouri River reservoir. Water Resour Res 29:1787-1804

Caradec S, Grossi V, Hulth S, Stora G, Gilbert F (2004) Macrofaunal reworking activities and hydrocarbon redistribution in an experimental sediment system. J Sea Res 52: 199-210

> Choi J, François-Carcaillet F, Boudreau BP (2002) Latticeautomaton bioturbation simulator (LABS): implementation for small deposit feeders. Comput Geosci 28:213-222

> Ciutat A, Gérino M, Mesmer-Dudons N, Anschutz P, Boudou A (2005) Cadmium bioaccumulation in Tubificidae from the overlying water source and effects on bioturbation. Ecotoxicol Environ Saf 60:237-246

> Cochran JK, Aller RC (1979) Particle reworking in sediments from the New York Bight apex: evidence from ${ }^{234} \mathrm{Th} /{ }^{238} \mathrm{U}$ disequilibrium. Estuar Coast Mar Sci 9:739-747

> Crusius J, Kenna TC (2007) Ensuring confidence in radionuclide-based sediment chronologies and bioturbation rates. Estuar Coast Shelf Sci 71:537-544

D'Andrea AF, Lopez GR, Aller RC (2004) Rapid physical and 
biological particle mixing on an intertidal sandflat. J Mar Res 62:67-92

Davis RB (1974) Stratigraphic effects of tubificids in profundal lake sediments. Limnol Oceanogr 19:466-488

Davison C (1891) On the amount of sand brought up by lobworms to the surface. Geol Mag 8:489-493

- Delmotte S, Meysman FJR, Ciutat A, Boudou A, Sauvage S, Gerino M (2007) Cadmium transport in sediments by tubificid bioturbation: an assessment of model complexity. Geochim Cosmochim Acta 71:844-862

Dobbs FC (1983) Monitoring defecation activity of infaunal deposit feeders. Mar Ecol Prog Ser 12:47-50

Duchêne JC, Nozais C (1994) Light influence on larval emission and vertical swimming in the terebellid worm Eupolymnia nebulosa (Montagu, 1818). Mem Mus Natl Hist Nat Ser A Zool 162:405-412

Duchêne JC, Queiroga H (2001) Use of an intelligent CCD camera for the study of endogenous vertical migration rhythms in first zoeae of the crab Carcinus maenas. Mar Biol 139:901-909

Dufour SC, Desrosiers G, Long B, Lajeunesse P and others (2005) A new method for three-dimensional visualisation and quantification of biogenic structures in aquatic sediments using axial tomodensitometry. Limnol Oceanogr Methods 3:372-380

Fernandes S, Meysman F, Sobral P (2006) The influence of $\mathrm{Cu}$ contamination on Nereis diversicolor bioturbation. Mar Chem 102:148-158

Fisher JB, Lick WJ, McCall PL, Robbins JA (1980) Vertical mixing of lake sediments by tubificid oligochaetes. J Geophys Res 85:3997-4006

Fornes WL, DeMaster D, Smith CR (2001) A particle introduction experiment in Santa Catalina Basin sediments: testing the age-dependent mixing hypothesis. J Sea Res 59:97-112

François F, Poggiale JC, Durbec JP, Stora G (1997) A new approach for the modelling of sediment reworking induced by a macrobenthic community. Acta Biotheor 45: 295-319

François F, Dalegre K, Gilbert F, Stora G (1999) Specific variability within functional groups: study of the sediment reworking of two Veneridae bivalves, Ruditapes decussatus and Venerupis aurea. CR Acad Sci Ser III Sci Vie 322: 339-345

François F, Poggiale JC, Durbec JP, Stora G (2001) A new model of bioturbation for a functional approach to sediment reworking resulting from macrobenthic communities. In: Aller JY, Woodin SA, Aller RC (eds) Organismsediment interactions. University of South Carolina Press, Columbia, p 73-86

François F, Gérino M, Stora G, Durbec JP, Poggiale JC (2002) Functional approach to sediment reworking by galleryforming macrobenthic organisms: modeling and application with the polychaete Nereis diversicolor. Mar Ecol Prog Ser 229:127-136

Fuller CC, Van Geen A, Baskaran M, Anima R (1999) Sediment chronology in San Francisco Bay, California, defined by ${ }^{210} \mathrm{~Pb},{ }^{234} \mathrm{Th},{ }^{137} \mathrm{Cs}$, and ${ }^{239,240} \mathrm{Pu}$. Mar Chem $64: 7-27$

Furukawa Y, Bentley SJ, Lavoie DL (2001) Bioirrigation modeling in experimental benthic mesocosms. J Mar Res 59: $417-452$

Gérino M (1990) The effects of bioturbation on particle redistribution in Mediterranean coastal sediment. Preliminary result. Hydrobiologia 207:251-258

Gérino M, Stora G, Durbec JP (1994) Quantitative estimation of biodiffusive and bioadvective sediment mixing: in situ experimental approach. Oceanol Acta 17:547-554

Gérino M, Aller RC, Lee C, Cochran JK, Aller JY, Green MA,
Hirschberg D (1998) Comparison of different tracers and methods used to quantify bioturbation during a spring bloom: 234-Thorium, luminophores and chlorophyll a. Estuar Coast Shelf Sci 46:531-547

Gielazyn ML, Stancyk SE, Piegorsch WW (1999) Experimental evidence of subsurface feeding by the burrowing ophiuroid Amphipholis gracillima (Echinodermata). Mar Ecol Prog Ser 184:129-138

Gilbert F, Bonin P, Stora G (1995) Effect of bioturbation on denitrification in a marine sediment from the West Mediterranean littoral. Hydrobiologia 304:49-58

Gilbert F, Hulth S, Stroemberg N, Ringdahl K, Poggiale JC (2003) 2-D optical quantification of particle reworking activities in marine surface sediments. J Exp Mar Biol Ecol 285/286:251-263

Gilbert F, Hulth S, Grossi V, Poggiale JC and others (2007) Sediment reworking by marine benthic species from the Gullmer Fjord (western Sweden): importance of faunal biovolume. J Exp Mar Biol Ecol 348:133-144

> Glass BP (1969) Reworking of deep-sea sediments as indicated by the vertical dispersion of the Australasian and Ivory Coast microtektite horizons. Earth Planet Sci Lett 6:409-415

Glass BP, Baker RN, Storzer D, Wagner GA (1973) North American microtektites from the Caribbean Sea and their fission track age. Earth Planet Sci Lett 19:184-192

Goldberg ED, Koide M (1962) Geochronological studies of deep sea sediments by the ionium/thorium method. Geochim Cosmochim Acta 26:417-450

> Green MA, Aller RC, Cochran JK, Lee C, Aller JY (2002) Bioturbation in shelf/slope sediments off Cape Hatteras, North Carolina: the use of ${ }^{234} \mathrm{Th}$, chl- ${ }$, and $\mathrm{Br}^{-}$to evaluate rates of particle and solute transport. Deep-Sea Res II 49:4627-4644

Grémare A, Amouroux JM, Charles F, Dinet A and others (1997) Temporal changes in the biochemical composition and nutritional value of the particulate organic matter available to surface deposit-feeders: a two year study. Mar Ecol Prog Ser 150:195-206

Guinasso NL, Schink DR (1975) Quantitative estimates of biological mixing in abyssal sediments. J Geophys Res 80:3032-3043

> Hansen R, Forbes TL, Westermann P (1999) Importance of bioturbation and feeding by the polychaete Capitella sp. I in the degradation of di(2-ethylexyl)phthalate (DEHP). Mar Ecol Prog Ser 182:187-199

> Hollertz K, Duchêne JC (2001) Burrowing behaviour and sediment reworking in the heart urchin Brissopsis lyrifera Forbes (Spatangoida). Mar Biol 139:951-957

Hughes DJ, Ansell AD, Atkinson RJA (1996) Sediment bioturbation by the echiuran worm Maxmuelleria lankesteri (Herdman) and its consequences for radionuclide dispersal in Irish Sea sediments. J Exp Mar Biol Ecol 195: 203-220

Hughes DJ, Brown L, Cook GT, Cowie G and others (2005) The effects of megafaunal burrows on radiotracer profiles and organic composition in deep-sea sediments: preliminary results from two sites in the bathyal north-east Atlantic. Deep-Sea Res I 52:1-13

Josefson AB, Forbes TL, Rosenberg R (2002) Fate of phytodetritus in marine sediments: functional importance of macrofaunal community. Mar Ecol Prog Ser 230:71-85

> Jumars PA, Self RFL, Nowell ARM (1982) Mechanics of particle selection by tentaculate deposit-feeders. J Exp Mar Biol Ecol 64:47-70

> Krezoski JR, Robbins JA, White DS (1984) Dual radiotracer measurement of zoobenthos-mediated solute and particle 
transport in freshwater sediments. J Geophys Res 89: 7937-7947

Kristensen E (2000) Organic matter diagenesis at the oxic/ anoxic interface in coastal marine sediments, with emphasis on the role of burrowing animals. Hydrobiologia 426: $1-24$

$>$ Kudenov JD (1982) Rates of seasonal sediment reworking in Axiothella rubrocincta (Polychaeta: Maldanidae). Mar Biol 70:181-186

Lecroart P, Schmidt S, Jouanneau JM, Weber O (2005) Be-7 and Th-234 as tracers of sediment mixing on seasonal time scale at the water-sediment interface of the Thau Lagoon. Radioprotection 40:661-667

Lecroart P, Schmidt S, Anschutz P, Jouanneau JM (2007a) Modeling sensitivity of biodiffusion coefficient to seasonal bioturbation. J Mar Res 65:417-440

Lecroart P, Schmidt S, Jouanneau JM (2007b) Numerical estimation of the error of the biodiffusion coefficient in coastal sediments. Estuar Coast Shelf Sci 72:543-552

Lee H, Swartz RC (1980) Biological processes affecting the distribution of pollutants in marine sediments. II: biodeposition and bioturbation. In: Baker RA (ed) Contaminants and sediments, Vol 2. Analysis, chemistry, biology. Ann Arbor Science Publishers, Ann Arbor, MI, p 555-606

Lohrer AM, Thrush SF, Gibbs MM (2004) Bioturbators enhance ecosystem function through complex biogeochemical interactions. Nature 431:1092-1095

Lohrer AM, Thrush SF, Hunt L, Hancock N, Lundquist C (2005) Rapid reworking of subtidal sediments by burrowing spatangoid urchins. J Exp Mar Biol Ecol 321:155-169

Lopez GR, Levington JS (1987) Ecology of deposit-feeding animals in marine sediments. Q Rev Biol 62:235-260

Madsen S, Forbes TL, Forbes VE (1997) Particle mixing by the polychaete Capitella sp. I: coupling fate and effect of a particle-bound organic contaminant (fluoranthene) in a marine sediment. Mar Ecol Prog Ser 147:129-142

Mahaut ML, Graf G (1987) A luminophore tracer technique for bioturbation studies. Oceanol Acta 10:323-328

- Mahon HK, Dauer DM (2005) Organic coatings and ontogenetic particle selection in Streblospio benedicti Webster (Spionidae: Polychaeta). J Exp Mar Biol Ecol 323:84-92

Maire O, Duchêne JC, Rosenberg R, Braga de Mendonça J Jr, Grémare A (2006) Effects of food availability on sediment reworking in Abra ovata and A. nitida. Mar Ecol Prog Ser 319:135-153

> Maire O, Duchêne JC, Grémare A, Malyuga VS, Meysman FJR (2007a) A comparison of sediment reworking rates by the surface deposit-feeding bivalve Abra ovata during summertime and wintertime, with a comparison between two models of sediment reworking. J Exp Mar Biol Ecol 343:21-36

Maire O, Duchêne JC, Bigot L, Grémare A (2007b) Linking feeding activity and sediment reworking in the depositfeeding bivalve Abra ovata with image analysis, laser telemetry, and luminophore tracers. Mar Ecol Prog Ser 351:139-150

> Maire O, Duchêne JC, Amouroux JM, Grémare A (2007c) Activity patterns in the terebellid polychaete Eupolymnia nebulosa assessed using a new image analysis system. Mar Biol 151:737-749

Meile C, van Cappellen P (2005) Particle age distribution and $\mathrm{O}_{2}$ exposure time: time scales in bioturbated sediments. Global Biogeochem Cycles 19:GB3013

> Mermillod-Blondin F, Marie S, Desrosiers G, Long B, de Montety L, Michaud E, Stora G (2003) Assessment of the spatial variability of intertidal benthic communities by axial tomodensitometry: importance of fine-scale heterogene- ity. J Exp Mar Biol Ecol 287:193-208

Mermillod-Blondin F, François-Carcaillet F, Rosenberg R (2005) Biodiversity of benthic invertebrates and organic matter processing in shallow marine sediments: an experimental study. J Exp Mar Biol Ecol 315:187-209

> Meysman FJR, Boudreau BP, Middelburg JJ (2003) Relations between local, nonlocal, discrete and continuous models of bioturbation. J Mar Res 61:391-410

> Meysman FJR, Galaktionov OS, Gribsholt B, Middelburg JJ (2006) Bio-irrigation in permeable sediments: an assessment of model complexity. J Mar Res 64:589-627

> Meysman FJR, Malyuga VS, Boudreau BP, Middelburg JJ (2007) The influence of porosity gradients on mixing coefficients in sediments. Geochim Cosmochim Acta 71: 961-973

Meysman FJR, Malyuga VS, Boudreau BP, Middelburg JJ (2008) Quantifying particle dispersal in aquatic sediments at short time scales: model selection. Aquat Biol 2:239-254

Miller RJ, Smith CR, DeMaster DJ, Fornes WL (2000) Feeding selectivity and rapid particle processing by deep-sea megafaunal deposit feeders: a ${ }^{234} \mathrm{Th}$ tracer approach. J Mar Res 58:653-673

Mugnai C, Gérino M, Frignani M, Sauvage S, Bellucci LG (2003) Bioturbation experiments in the Venice Lagoon. Hydrobiologia 494:245-250

Mulsow S, Landrum PF, Robbins JA (2002) Biological mixing responses to sublethal concentrations of DDT in sediments by Heteromastus filiformis using a ${ }^{137} \mathrm{Cs}$ marker layer technique. Mar Ecol Prog Ser 239:181-191

Nichols FH (1974) Sediment turnover by a deposit-feeding polychaete. Limnol Oceanogr 19:945-950

> Olmez I, Pink FX, Wheatcroft RA (1994) New particlelabelling technique for use in biological and physical sediment transport studies. Environ Sci Technol 28: $1487-1490$

> Ouellette D, Desrosiers G, Gagne JP, Gilbert F, Poggiale JC, Blier PU, Stora G (2004) Effects of temperature on in vitro sediment reworking processes by a gallery biodiffusor, the polychaete Neanthes virens. Mar Ecol Prog Ser 266: 185-193

> Peng TH, Broecker WS, Berger WH (1979) Rates of benthic mixing in deep sea sediments as determined by radioactive tracers. Quat Res 11:141-149

Pope RH, Demaster DJ, Smith CR, Seltman HJ (1996) Rapid bioturbation in equatorial Pacific sediments: evidence from excess ${ }^{234} \mathrm{Th}$ measurements. Deep-Sea Res II 43: 1339-1364

> Rabouille C, Gaillard JF (1991) A coupled model representing the deep-sea organic carbon mineralization and oxygen consumption in surficial sediments. J Geophys Res 96: 2761-2776

Reed DC, Huang K, Boudreau BP, Meysman FJR (2006) Steady-state tracer dynamics in a lattice-automaton model of bioturbation. Geochim Cosmochim Acta 70:5855-5867

Rhoads DC (1963) Rates of sediment reworking by Yoldia limatula in Buzzards Bay, Massachusetts, and Long Island Sound. J Sediment Petrol 33:723-727

Rhoads DC (1967) Biogenic reworking of intertidal and subtidal sediments in Barnstable Harbor and Buzzards Bay, Massachusetts. J Geol 75:461-476

Rhoads DC (1974) Organism-sediment relations on the muddy sea floor. Oceanogr Mar Biol Annu Rev 12:263-300

Rice DL (1986) Early diagenesis in bioadvective sediments: relationships between the diagenesis of beryllium-7, sediment reworking rates, and the abundance of conveyorbelt deposit-feeders. J Mar Res 44:149-184

Robbins JA (1986) A model for particle-selective transport of 
tracers in sediments with conveyor-belt deposit feeders. J Geophys Res 91:8542-8558

Rosenberg R, Davey E, Gunnarsson J, Norling K, Frank M (2007) Application of computer-aided tomography to visualize and quantify biogenic structures in marine sediments. Mar Ecol Prog Ser 331:23-34

Rosenberg R, Grémare A, Duchême JC, Davey E, Frank M (2008) 3D visualization and quantification of marine benthic biogenic structures and particle transport utilizing computer-aided tomography. Mar Ecol Prog Ser (in press)

Rowden AA, Jago CF, Jones SE (1998) Influence of benthic macrofauna on the geotechnical and geophysical properties of surficial sediment, North Sea. Cont Shelf Res 18: $1347-1363$

Roy H, Huettel M, Jorgensen BB (2002) The role of smallscale sediment topography for oxygen flux across the diffusive boundary layer. Limnol Oceanogr 47:837-847

Roy H, Huettel M, Jorgensen BB (2005) The influence of topography on the functional exchange surface of marine soft sediments, assessed from sediment topography measured in situ. Limnol Oceanogr 50:106-112

Sandnes J, Forbes T, Hansen R, Sandnes B, Rygg B (2000a) Bioturbation and irrigation in natural sediments, described by animal-community parameters. Mar Ecol Prog Ser 197:169-179

Sandnes J, Forbes T, Hansen R, Sandnes B (2000b) Influence of particle type and faunal activity on mixing of di(2-ethylhexyl)phthalate (DEHP) in natural sediments. Mar Ecol Prog Ser 197:151-167

Schmidt S, Gonzales JL, Lecroart P, Tronczynski J, Billy I, Jouanneau JM (2007) Bioturbation at the water-sediment interface of the Thau Lagoon: impact of shellfish farming. Aquat Living Resour 20:163-169

Sharma P, Gardner LR, Moore WS, Bollinger MS (1987) Sedimentation and bioturbation in a salt marsh as revealed by ${ }^{210} \mathrm{~Pb},{ }^{137} \mathrm{Cs}$, and ${ }^{7} \mathrm{Be}$ studies. Limnol Oceanogr 32:313-326

Shull DH (2001) Transition-matrix model of bioturbation and radionuclide diagenesis. Limnol Oceanogr 46:905-916

Shull DH, Yasuda M (2001) Size-selective downward particle transport by cirratulid polychaetes. J Sea Res 59:453-473

Smith JN, Boudreau BP, Noshkin V (1986) Plutonium and ${ }^{210} \mathrm{~Pb}$ distribution in northeast Atlantic sediments: subsurface anomalies caused by non-local mixing. Earth Planet Sci Lett 81:15-28

Smith CR, Pope RH, DeMaster DJ, Magaard L (1993) Agedependent mixing of deep-sea sediments. Geochim Cosmochim Acta 57:1473-1488

Soetaert K, Herman PMJ, Middelburg JJ, Heip C and others (1996) Modelling ${ }^{210} \mathrm{~Pb}$-derived mixing activity in ocean margin sediments: diffusive versus non local mixing. J Mar Res 54:1207-1227

Solan M, Wigham BD (2005) Biogenic particle reworking and bacterial-invertebrate interactions in marine sediments. In: Kristensen E, Haese RR, Kostka JE (eds) Interactions between macro- and microorganisms in marine sediments. Coastal and Estuarine Studies 60, American Geophysical Union, Washington, DC, p 105-124

Submitted: October 1, 2007; Accepted: March 12, 2008
Solan M, Wigham BD, Hudson IR, Kennedy R and others (2004) In situ quantification of bioturbation using timelapse fluorescent sediment profile imaging (f-SPI), luminophore tracers and model simulation. Mar Ecol Prog Ser 271:1-12

Stephens MP, Kadko DC, Smith CR, Latasa M (1997) Chlorophyll-a and pheopigments as tracers of labile organic carbon at the central equatorial Pacific seafloor. Geochim Cosmochim Acta 61:4605-4619

Stordal MC, Johnson JW, Guinasso NL, Schink DR (1985) Quantitative evaluation of bioturbation rates in deep ocean sediments. II. Comparison of rates determined by ${ }^{210} \mathrm{~Pb}$ and ${ }^{239,240} \mathrm{Pu}$. Mar Chem 17:99-114

Suchanek TH, Colin PL, McMurty GM, Suchanek CS (1986) Bioturbation and redistribution of sediment radionuclides in Enewetak Atoll lagoon by callianassid shrimp: biological aspects. Bull Mar Sci 38:144-154

Sun M, Aller RC, Lee C (1991) Early diagenesis of chlorophyll-a in Long Island Sound sediments: a measure of carbon flux and particle reworking. J Mar Res 49:379-401

> Sun MY, Lee C, Aller RC (1993) Laboratory studies of oxic and anoxic degradation of chlorophyll $a$ in Long Island Sound sediments. Geochim Cosmochim Acta 57:147-157

Taghon GL (1982) Optimal foraging by deposit-feeding invertebrates: roles of particle size and organic coating. Oecologia 52:295-304

Thomson J, Colley S, Weaver PPE (1988) Bioturbation into a recently emplaced deep-sea turbidite surface as revealed by ${ }^{210} \mathrm{~Pb}_{\text {excess }}{ }^{230} \mathrm{Th}_{\text {excess }}$ and planktonic foraminifera distributions. Earth Planet Sci Lett 90:157-173

Thomson J, Brown L, Nixon S, Cook GT, MacKenzie AB (2000) Bioturbation and Holocene sediment accumulation fluxes in the north-east Atlantic Ocean (benthic boundary layer experiment sites). Mar Geol 169:21-39

Turnewitsch R, Witte U, Graf G (2000) Bioturbation in the abyssal Arabian Sea: influence of fauna and food supply. Deep-Sea Res II 47:2877-2911

van Cappellen P, Wang Y (1996) Cycling of iron and manganese in surface sediments: a general theory for the coupled transport and reaction of carbon, oxygen, nitrogen, sulfur, iron, and manganese. Am J Sci 296:197-243

Wheatcroft RA (1991) Conservative tracer study of horizontal sediment mixing rates in a bathyal basin, California borderland. J Mar Res 49:565-588

> Wheatcroft RA (2006) Time-series measurements of macrobenthos abundance and sediment bioturbation intensity on a flood-dominated shelf. Prog Oceanogr 71:88-122

Wheatcroft RA, Jumars PA, Smith CR, Nowell ARM (1990) A mechanistic view of the particulate biodiffusion coefficient: step lengths, rest periods and transport directions. J Mar Res 48:177-207

- Wheatcroft RA, Olmez I, Pink FX (1994) Particle bioturbation in Massachusetts Bay: preliminary results using a new deliberate tracer technique. J Mar Res 52:1129-1150

White DS, Klahr PC, Robbins JA (1987) Effects of temperature and density on sediment reworking by Stylodrilus heringianus (Oligochaeta: Lumbriculidae). J Gt Lakes Res 13: $147-156$

Proofs received from author(s): May 26, 2008 